Portland State University

PDXScholar

$11-2009$

\title{
Surfing the Waves of Globalization: Asia and Financial Globalization in the Context of Trilemma
}

\author{
Joshua Aizenman \\ University of California, Santa Cruz \\ Menzie David Chinn \\ University of Wisconsin-Madison
}

Hiro Ito

Portland State University

Follow this and additional works at: https://pdxscholar.library.pdx.edu/econ_fac

Part of the International Economics Commons

Let us know how access to this document benefits you.

\section{Citation Details}

Aizenman, Joshua, Menzie D. Chinn, and Hiro Ito. "Surfing the waves of globalization: Asia and financial globalization in the context of the trilemma."Journal of the Japanese and International Economies 25.3 (2011): 290-320.

This Working Paper is brought to you for free and open access. It has been accepted for inclusion in Economics Faculty Publications and Presentations by an authorized administrator of PDXScholar. Please contact us if we can make this document more accessible: pdxscholar@pdx.edu. 


\section{ADB Economics Working Paper Series}
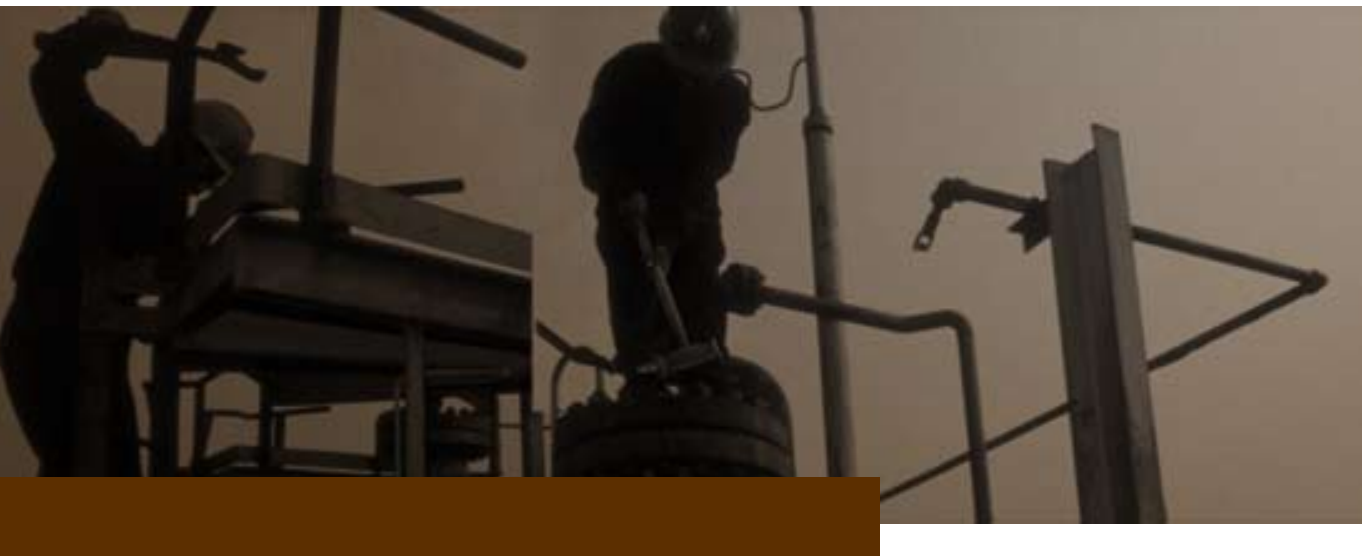

Surfing the Waves of Globalization:

Asia and Financial Globalization

in the Context of the Trilemma

Joshua Aizenman, Menzie D. Chinn, and Hiro Ito

No. 180 | November 2009

Asian Development Bank 



\title{
Surfing the Waves of Globalization: Asia and Financial Globalization in the Context of the Trilemma
}

\author{
Joshua Aizenman, Menzie D. Chinn, and Hiro Ito
}

November 2009

Joshua Aizenman is Professor at the Department of Economics, University of California Sta Cruz; Menzie D. Chinn is Professor at the Robert M. La Follette School of Public Affairs and Department of Economics, University of Wisconsin; and Hiro Ito is Professor at the Department of Economics, Portland State University.

This paper was initially prepared as a background material for the Asian Development Bank's (ADB) Asian Development Outlook 2009 Update (www.adb.org/Economics/). The authors thank Akiko Terada-Hagiwara and Jong-Wha Lee for their valuable comments. Prof. Ito thanks the ADB Institute for its hospitality during his stay as a visiting scholar, during which time part of this paper was completed. The financial support of faculty research funds of Portland State University is also gratefully acknowledged. The views expressed herein are those of the authors and not necessarily those of ADB or ADB Institute.

\section{Asian Development Bank}


Asian Development Bank

6 ADB Avenue, Mandaluyong City

1550 Metro Manila, Philippines

www.adb.org/economics

C2009 by Asian Development Bank

November 2009

ISSN 1655-5252

Publication Stock No. WPS09

The views expressed in this paper

are those of the author(s) and do not

necessarily reflect the views or policies

of the Asian Development Bank.

The ADB Economics Working Paper Series is a forum for stimulating discussion and eliciting feedback on ongoing and recently completed research and policy studies undertaken by the Asian Development Bank (ADB) staff, consultants, or resource persons. The series deals with key economic and development problems, particularly those facing the Asia and Pacific region; as well as conceptual, analytical, or methodological issues relating to project/program economic analysis, and statistical data and measurement. The series aims to enhance the knowledge on Asia's development and policy challenges; strengthen analytical rigor and quality of ADB's country partnership strategies, and its subregional and country operations; and improve the quality and availability of statistical data and development indicators for monitoring development effectiveness.

The ADB Economics Working Paper Series is a quick-disseminating, informal publication whose titles could subsequently be revised for publication as articles in professional journals or chapters in books. The series is maintained by the Economics and Research Department. 


\section{Contents}

Abstract $\quad v$

I. Introduction 1

II. The "Impossible Trinity" or "Trilemma": Theory and Evidence 3

A. Brief Review of the Theory 3

B. The "Trilemma Indexes" 6

C. Development of the Trilemma Dimensions 7

III. Regression Analyses 10

A. Estimation Results of the Basic Models 12

B. Implications for Asia 28

C. Further Investigation into Output Volatility and Trilemma Choices 31

D. Policy Implications and Asia 33

V. Concluding Remarks 39

Appendix 1: Construction of the Trilemma Measures 42

Appendix 2: List of "Asian Economies" in the Sample $\quad 44$

$\begin{array}{ll}\text { References } & 45\end{array}$ 



\begin{abstract}
Using the "trilemma indexes" developed by Aizenman et al. (2008) that measure the extent of achievement in each of the three policy goals in the trilemmamonetary independence, exchange rate stability, and financial openness-this paper examines how policy configurations affect macroeconomic performances with focus on the Asian economies. We find that the three policy choices do not matter for per capita economic growth. However, they do matter for output volatility and the medium-term level of inflation. Greater monetary independence is associated with lower output volatility while greater exchange rate stability implies greater output volatility, which can be mitigated if a country holds international reserves (IR) at a higher level than a threshold (about $20 \%$ of gross domestic product). Greater monetary autonomy is associated with a higher level of inflation while greater exchange rate stability and greater financial openness could lower the inflation level. We find that trilemma policy configurations and external finances affect output volatility mainly through the investment channel. While a higher degree of exchange rate stability could stabilize the real exchange rate movement, it could also make investment volatile, though the volatilityenhancing effect of exchange rate stability on investment can be cancelled by holding higher levels of IR. Greater financial openness helps reduce real exchange rate volatility. These results indicate that policy makers in a more open economy would prefer pursuing greater exchange rate stability and greater financial openness while holding a massive amount of IR. Asian emerging market economies are found to be equipped with macroeconomic policy configurations that help the economies to dampen the volatilities in both investment and real exchange rate. These economies' sizeable amount of international reserves holding appears to help enhance the stabilizing effect of the trilemma policy choices, which explains the recent phenomenal buildup of international reserves in the region.
\end{abstract}





\section{Introduction}

Originating from the financial crisis in the United States (US), the waves of the global crisis quickly hit hard so many countries, including those in Asia, in the summer of 2008, devastating economies on a global scale by the end of 2008. According to the International Monetary Fund (IMF), all of the US, the Euro area, and Japan are expected to experience negative output growth in 2009 for the first time in the post-World War II era. Emerging and developing economies are expected to grow at a mere $1.7 \%$, plunging from $8.3 \%$ in 2007 and $6.0 \%$ in 2008 . Asia is no exception; newly industrialized Asian economies are expected to shrink by $2.4 \%$ in 2009 , and the two high-growth economies in Asia, People's Republic of China (PRC) and India, are predicted to significantly slow down to $7.5 \%$ and $5.4 \%$, respectively. Clearly, countries have experienced the worst global economic crisis since the Great Depression of the 1930s.

By the summer of 2009, however, there are some, but mosaic, signs of recovery among some countries. Even the US, the epicenter of the crisis, started to show some signs of recovery by the fall of 2009 . Although smaller economies seem to continue to be in a frail situation, bigger emerging economies in Asia started reporting economic data that suggest robust recovery. In the second quarter of 2009, emerging Asian economies' gross domestic product (GDP) grew at an average annualized rate of over $10 \%$ while the US' fell by $1 \%$. As of 23 July 2009, the Asian Development Bank Chief Economist Jong-Wha Lee commented "Emerging East Asia could see a V-shaped recovery, with growth dipping sharply in 2009 before regaining last year's pace in 2010."1

The V-shaped recovery in Asia, if that ever happens, is not unprecedented. In fact, that is how many economies in the region reacted to the Asian crisis of 1997/1998. Despite a severe output contraction in 1998, Asian crisis economies did make a remarkable comeback with robust growth in exports and output as early as in 1999. Park and Lee (2002) attribute the quick comeback of the crisis-inflicted economies to their openness and close link to the rest of the world. Asia's quick bounce this time is not only impressive but also surprising given that, unlike in the aftermath of the Asian crisis, the US economy does not provide the "demand of last resort" (Aizenman and Jinjarak, 2008) that can fill the foregone demand in the world economy.

1 Asian Development Bank News Release on 23 July 2009, www.adb.org/Media/Articles/2009/12944-east-asianeconomics-growths/ 
If the Asian economies could show robust and sustainable recovery while the advanced economies do not, that could involve two implications. First, robust recovery can be interpreted as evidence for the Asian economies "decoupling" from the advanced economies. Second, it could also mean that economies in the Asian region, most of which are quite open to international trade in goods and financial assets, are better prepared to cope with economic crises in a highly globalized environment. Figure 1 shows that output volatility-measured by the standard deviations of per capita output growth rates-for Asian emerging market economies has been maintained at low levels comparable to those of the industrialized countries. This suggests that these economies may have adopted international economic policies that allow them to experience better macroeconomic performance. While we still have to wait a few more years to conduct meaningful analysis on the "decoupling" issue, we can investigate whether Asian economies are better-suited to cope with globalization by examining what has happened. This will be the main focus of this paper.

Figure 1: Output Volatility, 1972 - 2006

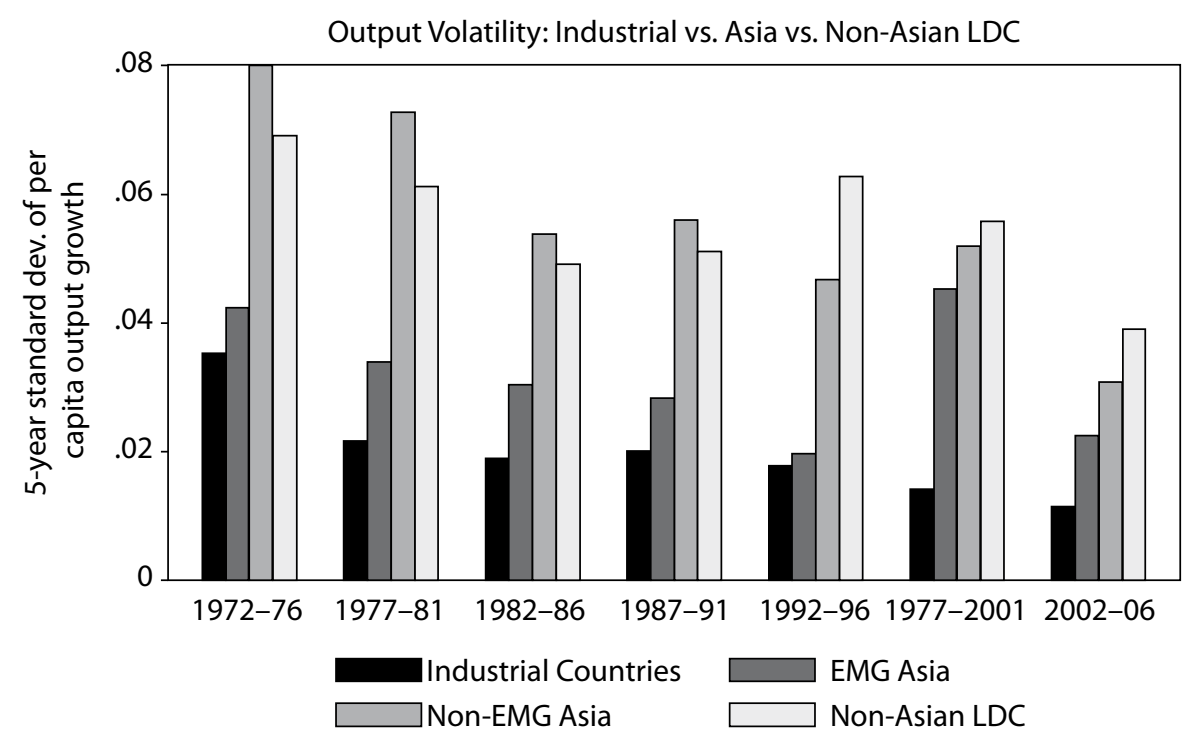

DMG = emerging market economies, LDC = less developed country.

Notes: Output volatility is measured by 5 -year standard deviations of the growth rate of per capita output. The data for per capita output are extracted from the Penn World Table database. Appendix 2 shows the countries included as "EMG Asia" or emerging market economies in Asia.

To examine policy configurations in the context of international macroeconomics, this paper focuses on a very powerful hypothesis in international finance called the "impossible trinity," or the "trilemma." The hypothesis states that a country may simultaneously choose any two, but not all, of the following three goals: monetary independence, exchange rate stability, and financial integration. This concept, if valid, is supposed to constrain policy makers by forcing them to choose only two out of the three policy choices. In fact, among many international monetary and financial arrangements that have been in place since the Gold Standard system, each set of arrangements imposed different choices on countries. 
Given that Asian emerging market economies have collectively outperformed other developing economies in terms of output growth stability, it can be their international macroeconomic policy management, determined within the constraint of the trilemma, that have contributed to making these economies better prepared for higher vulnerability possibly exacerbated by recent globalization.

As such, this paper will investigate how policy configurations based on the trilemma affect the macroeconomic performance of the economies, with focus on emerging markets in Asia. Given the complexity of the dynamics of policy choices and macroeconomic performances, it is most appropriate and effective to conduct panel data analysis to unravel the peculiarity, if there is, of international macroeconomic policies of these economies. More specifically, using the "trilemma indexes" developed by Aizenman et al. (2008) that measure the extent of achievement in each of the three policy goals, this paper will examine how policy configurations based on the trilemma affect macroeconomic performances such as output growth, output volatility, inflation volatility, and the medium rate of inflation for developing countries.

Furthermore, this study focuses on output volatility and attempts to identify the channels by which the trilemma policy choices affect output volatility. As candidate channels, the volatilities of investment and the real exchange rate will be examined. This exercise should yield inferences about how policy configurations can differ depending on the extent of openness of the economy.

Section 2 briefly reviews the theory of the trilemma and also assesses the development of the three macroeconomic policies based on the trilemma by using the "trilemma indexes." Section 3 conducts a more formal analysis on how the policy choices affect macroeconomic policy goals, namely, output growth, output volatility, inflation rates, and the volatility of inflation. We will examine the implications of the estimation results for Asian economies. In Section 4, we extend our empirical investigation to investigate the channels by which international macroeconomic policy configurations affect output volatility. Section 5 presents concluding remarks.

\section{The "Impossible Trinity" or "Trilemma": Theory and Evidence}

\section{A. Brief Review of the Theory}

Although it is debatable whether the worst is over for the current global crisis, it at least has put the current international financial architecture or individual countries' international macroeconomic policies into question as symbolized by the series of G20 meetings in Washington, D.C., London, and Pittsburgh. Some commentators emphasized the 
G20 meetings' parallelism to the series of meetings to determine the post-World War II international financial architecture held in 1944 in Bretton Woods, New Hampshire.

Whatever configuration of international financial architecture or international macroeconomic policies policy makers consider, conceptually, they cannot avoid confronting the "impossible trinity," or the "trilemma"-a hypothesis that states that a country simultaneously may choose any two, but not all, of the three goals of monetary independence, exchange rate stability, and financial integration.

The trilemma is illustrated in Figure 2. Each of the three sides-representing monetary independence, exchange rate stability, and financial integration-depicts a potentially desirable goal, yet it is not possible to be simultaneously on all three sides of the triangle. The top vertex, labeled "closed capital markets", is, for example, associated with monetary policy autonomy and a fixed exchange rate regime, but not financial integration. $^{2}$

\section{Figure 2: The Trilemma}

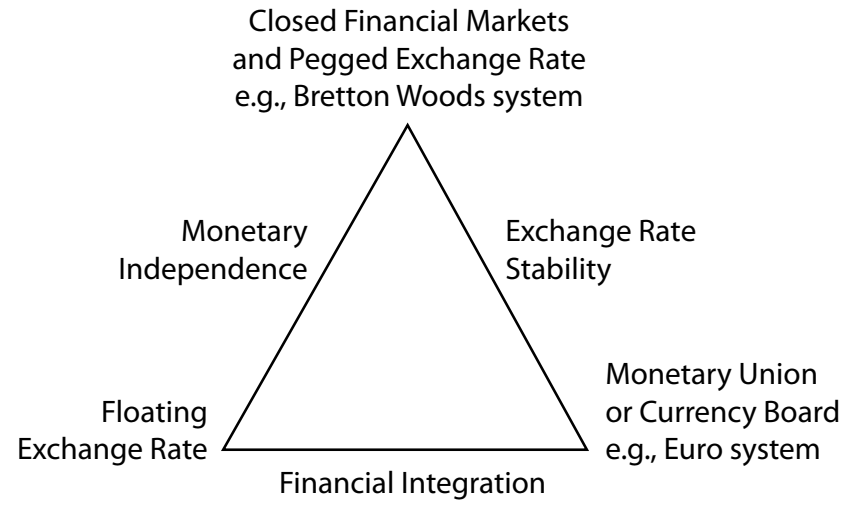

Since the Gold Standard system, different international financial systems have attempted to achieve combinations of two out of the three policy goals. The Bretton Woods system sacrificed capital mobility for monetary autonomy and exchange rate stability. The Euro system is built upon the fixed exchange rate arrangement and free capital mobility, but abandoned monetary autonomy of the member countries. For many years until recently, developing countries had pursued monetary independence and exchange rate stability, but kept their financial markets closed to foreign investors.

The fact that countries have adopted combinations of two out of the three policy choices and altered the combinations as a reaction to crises or major economic events must mean that each of the three policy options is a mixed bag of both merits and demerits for managing macroeconomic conditions.

2 See Obstfeld, Shambaugh, and Taylor (2005) for further discussion and references dealing with the trilemma. 
Monetary independence allows the monetary authorities of an economy to have autonomy over its macroeconomic management. An economy with a high degree of monetary independence should be able to stabilize the economy through monetary policy without being subject to other economies' macroeconomic management. Hence, monetary independence can potentially lead to stable and sustainable economic growth. However, in a world with price and wage rigidities, policy makers can manipulate output movement (at least in the short-run), which means that policy makers with greater monetary autonomy could lead to increasing output and inflation volatility. Furthermore, it is also possible that monetary authorities abuse their autonomy to monetize fiscal debt, and therefore end up destabilizing the economy through high and volatile inflation.

Exchange rate stability could bring out price stability by providing an anchor, lessening risk premium by mitigating uncertainty, thereby fostering investment and international trade. ${ }^{3}$ Also, at the time of an economic crisis, maintaining a pegged exchange rate could increase the credibility of policy makers and thereby contribute to stabilizing output movement (Aizenman, et al., 2009). However, greater levels of exchange rate fixity could also rid policy makers of a policy choice of using exchange rate as a tool to absorb external shocks. Prasad (2008) argues that exchange rate rigidities would prevent policy makers from implementing appropriate policies consistent with macroeconomic reality, so that they would be prone to cause asset boom and bust through overheating the economy. Hence, the rigidity caused by exchange rate fixity could not only enhance output volatility, but also cause misallocation of resources and unbalanced, unsustainable growth.

Financial liberalization is probably the most contentious and hotly debated policy among the three. Theory predicts that more open financial markets could lead to economic growth through more efficient resource allocation, mitigating information asymmetry, enhancing and/or supplementing domestic savings, and helping transfer of technological or managerial know-how (i.e., growth in total factor productivity). ${ }^{4}$ Also, economies with greater access to international capital markets should be able to stabilize themselves through risk sharing and portfolio diversification. However, as financial liberalization increased its pace over the last two decades, financial openness gets the blame for economic instability for these years as was the case in a series of crises in the late 1990s and the current crisis. Based on this view, financial openness could expose economies to volatile cross-border capital flows including sudden stop or reversal of capital flows, thereby making economies face boom-bust cycles (Kaminsky and Schmukler, 2002). ${ }^{5}$

3 Aghion, et al. (2005) argue that, for an economy equipped with well-developed financial markets, reduction in uncertainty could enhance more efficient allocation of capital that could lead to higher productivities.

4 Henry (2006) argues that only when it fundamentally changes productivity growth through financial market development could equity market liberalization policies have a long-term effect on investment and output growth. Otherwise, the effect of financial liberalization should be shortlived, which may explain the weak evidence on the link between financial liberalization and growth.

5 For a summary on the cost and benefits of financial liberalization, refer to Henry (2006) and Prasad and Rajan (2008). 
Thus, theory tells us that each one of the three trilemma policy choices can be a doubleedged sword, which should explain the wide and mixed variety of empirical findings on each of the three policy choices. ${ }^{6}$ Furthermore, to make matters more complicated, while there are three ways of pairing two out of the three policies (i.e., three vertexes in the triangle in Figure 2), the effect of each policy choice can differ depending on the policy choice it is paired with. For example, exchange rate stability can be more destabilizing when it is paired with financial openness. But if it is paired with greater monetary autonomy (i.e., closed financial markets), it can be stabilizing. Hence, the three types of policy combinations may as well be subject to empirical scrutiny, which needs to be done in comprehensive and systematic ways.

\section{B. The "Trilemma Indexes"}

Despite its pervasive recognition, there has been almost no empirical work that tests the concept of the trilemma systematically. Many of the studies in this literature often focus on one or two variables of the trilemma, but fail to provide comprehensive analysis on all of the three policy aspects of the trilemma. ${ }^{7}$ This is partly because of the lack of appropriate metrics that measure the extent of achievement in the three policy goals.

Aizenman et al. (2008) overcame this deficiency by developing a set of the "trilemma indexes" that measure the degree of three policy choices countries make with respect to the trilemma. Using these indexes, we tested whether the indexes are linearly related to each other, and we confirmed that a change in one of the trilemma variables would induce a change with the opposite sign in the weighted average of the other two. This means, as theory predicts, countries do face the trade-off of the three policy choices. ${ }^{8}$

The "trilemma indexes" are created for more than 170 countries for 1970 through 2007. The monetary independence index (MI) is based on the correlation of a country's interest rates with the base country's interest rate. The index for exchange rate stability (ERS) is an invert of the exchange rate volatility, i.e., standard deviations of the monthly rate of depreciation, for the exchange rate between the home and base countries. The degree of financial integration is measured with the Chinn-Ito $(2006,2008)$ capital controls index (KAOPEN). More details on the construction of the indexes can be found in the Appendix 1.

6 Monetary independence is often discussed in the context of the impact of central bank independence or inflation targeting such as Alesina and Summers (1993) and Cechetti and Ehrmann (1999) among many others. On the impact of the exchange rate regime, refer to Ghosh et al. (1997), Levy-Yeyati and Sturzenegger (2003), and Eichengreen and Leblang (2003). The empirical literature on the effect of financial liberalization is surveyed by Edison et al. (2002), Henry (2006), Kawai and Takagi (2008), and Prasad et al. (2003).

7 Of course, the notable exceptions include the papers by Obstfeld, Shambaugh, and Taylor (2005, 2008, and 2009) and Shambaugh (2004).

8 We also showed that major crises in the last four decades, namely, the collapse of the Bretton Woods system, the debt crisis of 1982, and the Asian crisis of 1997/1998, caused structural breaks in the trilemma configurations. 


\section{Development of the Trilemma Dimensions}

Comparing theses indexes provides interesting insights into how the international financial architecture has evolved. Figure 3 shows the trajectories of the trilemma indexes for different income country groups. For the industrialized countries, financial openness accelerated after the beginning of the 1990s while the extent of monetary independence has started a declining trend. After the end of the 1990s, exchange rate stability rose significantly. All these trends reflect the introduction of the euro in $1999 .{ }^{9}$

Figure 3: Development of the Trilemma Configurations Over Time

(a) Industrialized Countries

MI, ERS, and KAOPEN, IDC

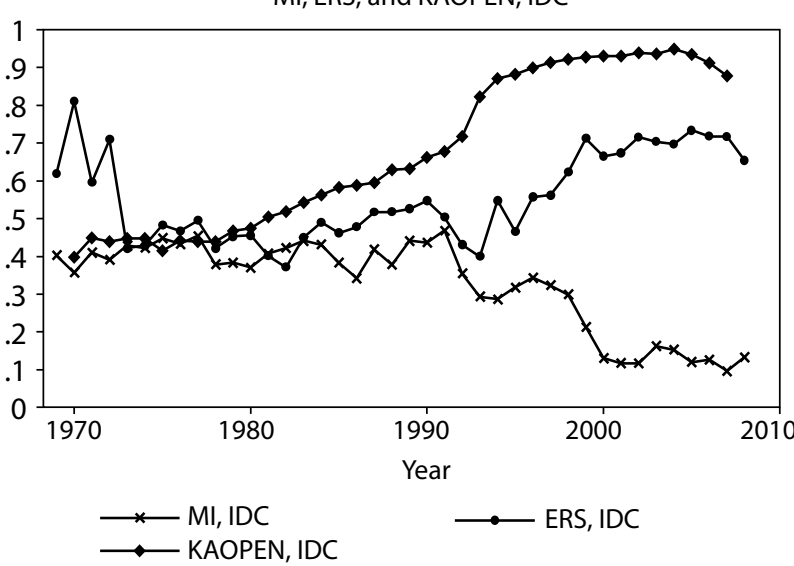

(c) Non-Emerging Market Developing Countries

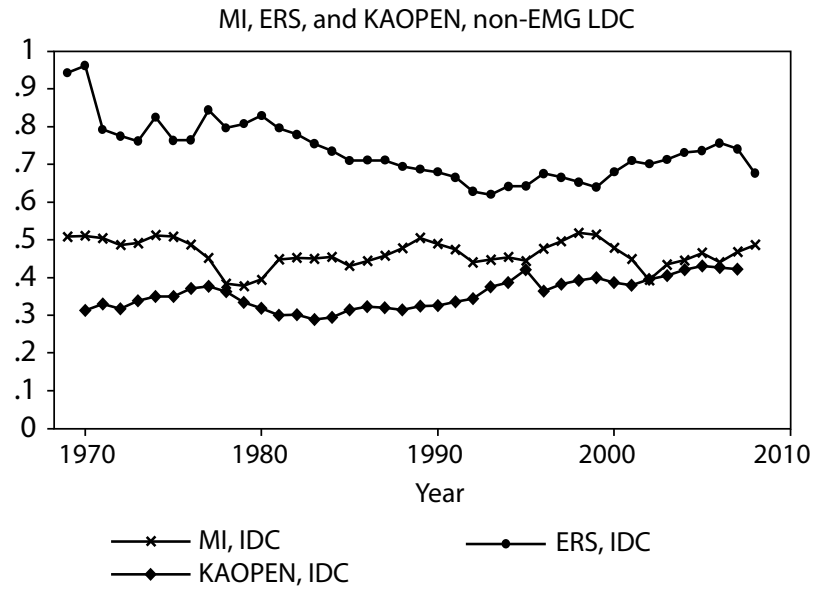

(b) Emerging Market Economies $\mathrm{MI}, \mathrm{ERS}$, and KAOPEN, EMG

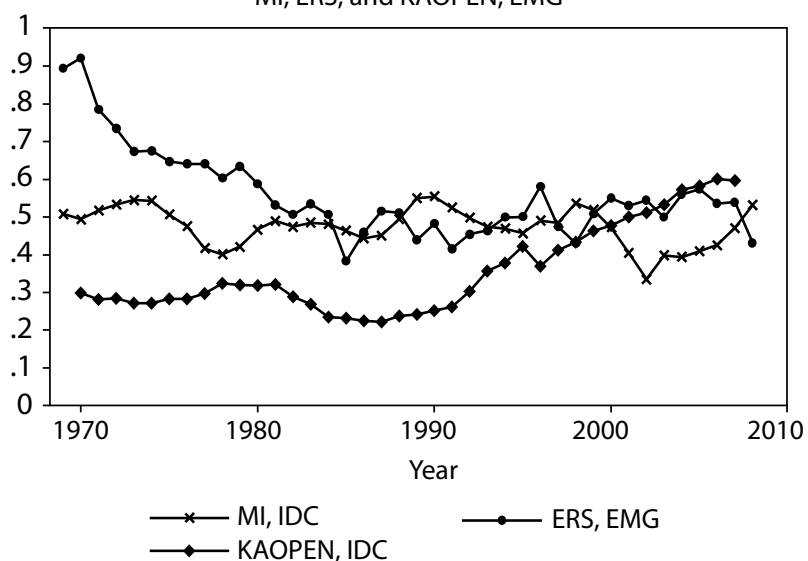

$E M G=$ emerging market economies, $E R S=$ exchange rate stability, IDC $=$ industrialized countries, $\mathrm{KAOPEN}=$ capital account openness, $\mathrm{LDC}=$ less developed country, $\mathrm{MI}=$ monetary independence.

9 If the euro countries are removed from the sample (not reported), financial openness evolves similarly to the industrialized countries group that includes the euro countries, but exchange rate stability hovers around the line for monetary independence, though at a bit higher levels, after the early 1990s. The difference between exchange rate stability and monetary independence has been slightly diverging after the end of the 1990s. 
Developing countries on the other hand do not present such a distinct divergence of the indexes, and their experiences differ depending on whether they are emerging or non-emerging market ones. ${ }^{10}$ For emerging market economies, exchange rate stability declined rapidly from the 1970 s through the mid-1980s. After some retrenchment after the early 1980s (in the wake of the debt crisis), financial openness started rising from 1990 onward. For the other developing countries, exchange rate stability declined less rapidly, and financial openness trended upward more slowly. In both cases, though, monetary independence remained more or less trendless.

Interestingly, for the emerging market economies, the indexes suggest a convergence toward the middle ground, even as talk of the disappearing middle rose in volume. This pattern of results suggests that developing countries may have been trying to cling to moderate levels of both monetary independence and financial openness while maintaining higher levels of exchange rate stability-leaning against the trilemma in other wordswhich interestingly coincides with the period when some of these economies started holding sizable international reserves, potentially to buffer the trade-off arising from the trilemma. ${ }^{11}$

None of these observations are applicable to non-emerging developing market countries (Figure 3[c]). For this group of countries, exchange rate stability has been the most aggressively pursued policy throughout the period. In contrast to the experience of the emerging market economies, financial liberalization is not proceeding rapidly for the nonemerging market developing economies.

To shed further light on the concept of the trilemma, adding one more dimension to the three trilemma dimensions is helpful. That is the role of international reserves (IR) holding. Since the Asian crisis of 1997/1998, developing countries, especially those in East Asia and the Middle East, have been rapidly increasing the amount of IR holding. The PRC, the world's largest holder of IR, currently holds about $\$ 2$ trillion of reserves, accounting for $30 \%$ of the world's total. As of the end of 2008 , the top 10 biggest holders are all developing countries, with the sole exception of Japan. The nine developing countries, including PRC, Republic of Korea (Korea), Russian Federation, and Taipei,China, hold about $50 \%$ of world IR. Against this backdrop, it has been argued that one of the main reasons for the rapid IR accumulation is countries' desire to stabilize exchange rate movement. One perspective holds that countries accumulate massive IR to achieve some target combination of exchange rate stability, monetary policy autonomy, and financial openness.

10 The emerging market economies are defined as the countries classified as either emerging or frontier during 1980-1997 by the International Financial Corporation. For those in Asia, emerging market economies are "Emerging East Asia-14" defined by Asian Development Bank plus India.

11 Willett (2003) has called this compulsion by countries with a mediocre level of exchange rate fixity to hoard reserves the "unstable middle" hypothesis (as opposed to the "disappearing middle" view). 
For example, a country pursuing a stable exchange rate and monetary autonomy may try to liberalize cross-border financial transactions while determined not to give up the current levels of exchange rate stability and monetary autonomy. This sort of policy combination, however, could make the monetary authorities motivated to hold a sizeable amount of IR so that they can stabilize the exchange rate movement while retaining monetary autonomy. Or, if an economy with open financial markets and fixed exchange rate faces a need to lax monetary policy independently, it may be able to do so-though temporarilyas long as it holds a massive amount of IR. Thus, evidently, one cannot discuss the issue of the trilemma without incorporating a role for IR holding.

The "Diamond charts" in Figure 4 are useful in tracing the changing patterns of the trilemma configurations while incorporating IR holding. Each country's configuration at a given instant is summarized by a "generalized diamond", whose four vertices measure

\section{Figure 4: The "Diamond Charts": Variation of the Trilemma and IR Configurations Across Different Country Groups}
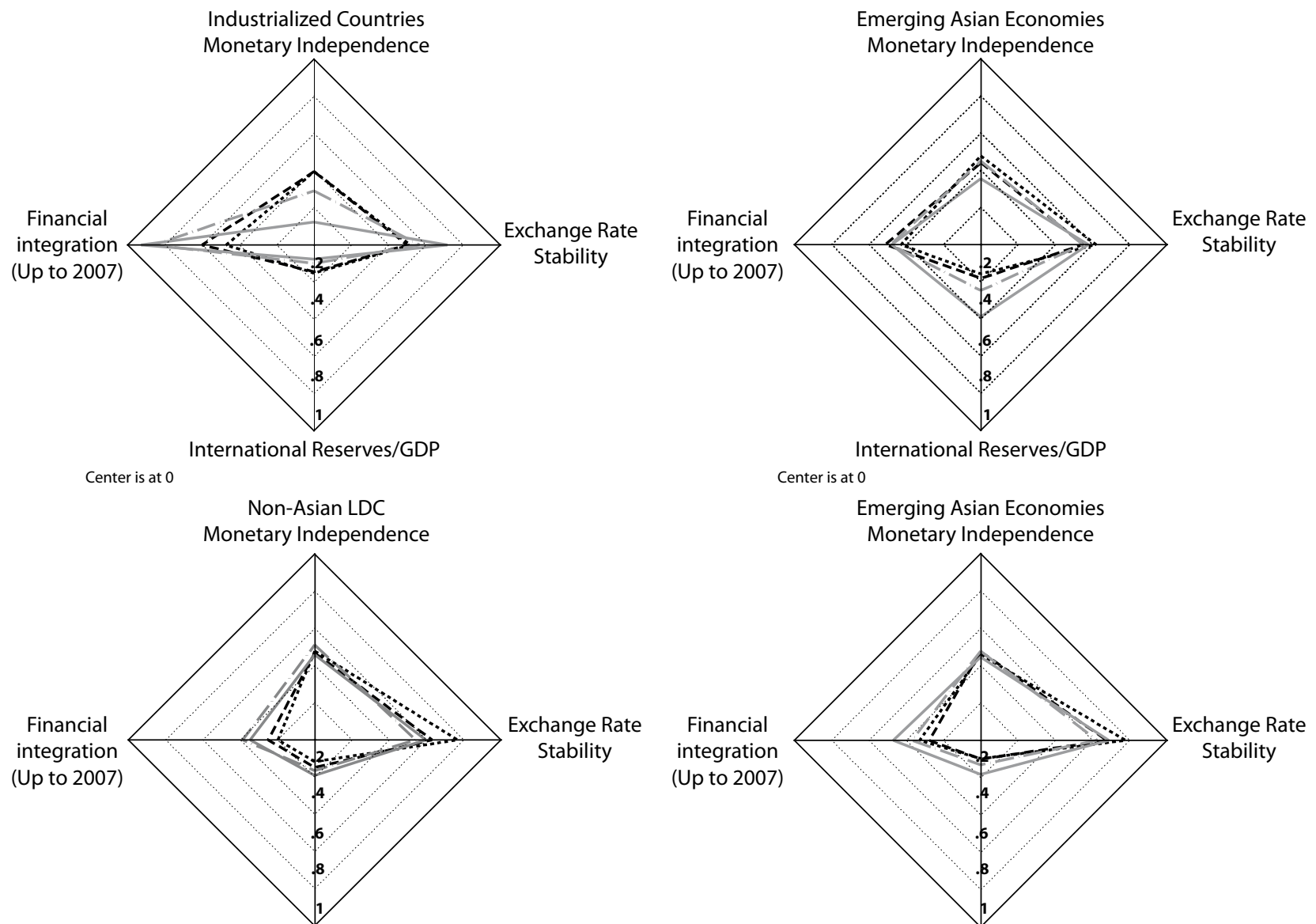

International Reserves/GDP

Center is at 0
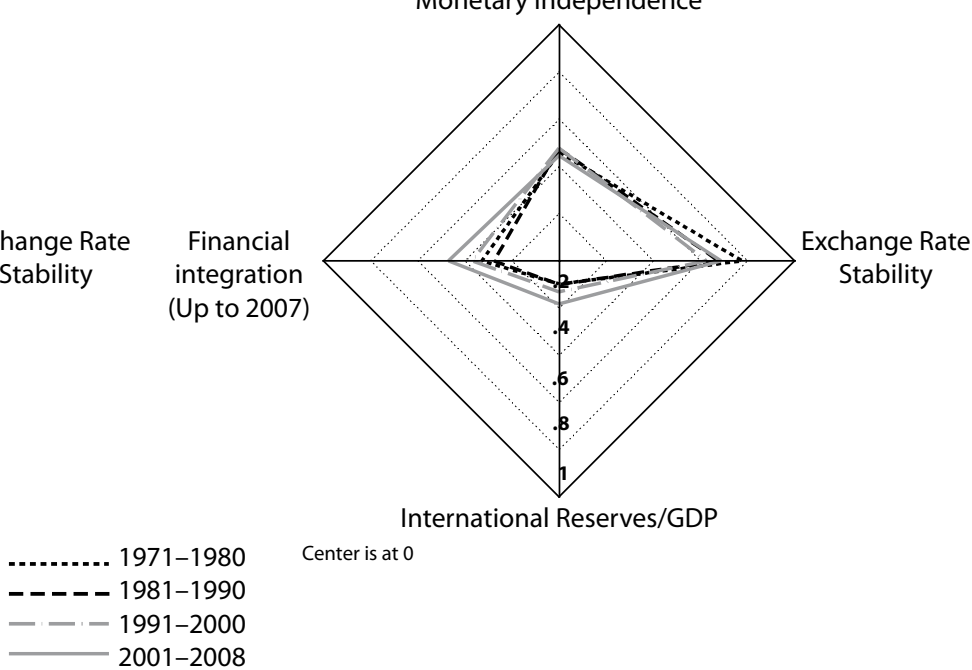

International Reserves/GDP

Center is at 0

$--1991-2000$

2001-2008

$\mathrm{GDP}=$ gross domestic product, $\mathrm{LDC}=$ less developed country, IR = international reserves. 
monetary independence, exchange rate stability, IR/GDP, and financial integration with the origin normalized so as to represent zero monetary independence, pure float, zero international reserves, and financial autarky. Figure 4 summarizes the trends for industrialized countries, emerging Asian economies, non-emerging market developing Asian countries, non-Asian developing countries, and Latin American emerging market economies.

In Figure 4, we can observe again the divergence of the trilemma configurations for the industrial economies-a move toward deeper financial integration, greater exchange rate stability, and weaker monetary independence over the years. But this group of countries has reduced the level of IR holding over years unlike the other country groups. Once we shift our attention to regional comparison of the trilemma configurations, Asia, especially those economies with emerging markets, looks distinct from other groups of countries. ${ }^{12}$ The diamond chart for Asian emerging market economies shows that the middle-ground convergence we observed for the emerging market economies group in Figure 3 is quite evident for this group of economies, and that it is not a recent phenomenon for these economies. Since as early as the 1980s, the three indexes have been clustered around the middle range, although exchange rate stability is the most pervasive policy choice and the degree of monetary independence has been gradually dropping. This characterization does not appear to be applicable to the other groups of developing economies, whether or not they are Asian. Latin American emerging market economies appear to have gone through a distinctively different path of development compared to the Asian counterparts. Most importantly, the group of Asian emerging market economies stands out from the others with their sizeable and rapidly increasing amount of IR holding, which may make one suspect potential implications of such IR holdings on trilemma policy choices and macroeconomic performances.

\section{Regression Analyses}

Although the above characterization of the trilemma indexes allows us to observe the development of policy orientation among countries, it fails to identify countries' motivations for policy changes. Hence, we examine econometrically how the various choices regarding the three policies affect final policy goals, namely, high economic growth, output growth stability, low inflation, and inflation stability.

The estimation model is given by:

$$
y_{i t}=\alpha_{0}+\alpha_{1} T L M_{i t}+\alpha_{2} I R_{i t}+\alpha_{3}\left(T L M_{i t} \times I R_{i t}\right)+X_{i t} \mathrm{~B}+Z_{t} \Gamma+D_{i} \Phi+\varepsilon_{i t}
$$

$y_{i t}$ is the measure of macro policy performance for country $i$ in year $t$, i.e., per capita

12 Appendix 2 lists the "Asian Economies" included in the sample. 
output growth, output volatility, inflation volatility, and the medium-term level of inflation. ${ }^{13} T L M_{i t}$ is a vector of any two of the three trilemma indexes, namely, MI, ERS, and KAOPEN. Aizenman et al. (2008) have shown that these three measures of the trilemma are linearly related. Therefore, it is most appropriate to include two of the indexes simultaneously, rather than individually or all three jointly. ${ }^{14} T R_{i t}$ is the level of international reserves (excluding gold) as a ratio to GDP, and $\left(T L M_{i t} \times T R_{i t}\right)$ is an interaction term between the trilemma indexes and the level of IR, that may allow us to observe whether IR complements or substitutes for other policy stances.

$X_{i t}$ is a vector of macroeconomic control variables that include the variables most used in the literature. More specifically, for the estimation on economic growth, $X_{i t}$ includes income per capita from the initial year of each 5-year panel, average investment ratio to GDP, years of schooling (based on Barro and Lee, 2001), population growth, trade openness $(=(E X+I M) / G D P)$, and private credit creation (percent of GDP) as a measure of financial development. The regressions on output volatility, inflation volatility, and the level of inflation include relative income (to the US per capita real income-based on Penn World Table), its quadratic term, trade openness, the terms-of-trade (TOT) shock defined as the 5-year standard deviation of trade openness times TOT growth, fiscal procyclicality (measured as the correlations between Hodrick-Prescott (HP)-detrended government spending series and HP-detrended real GDP series), 5-year average of M2 growth, private credit creation (as percent of GDP), the inflation rate, and inflation volatility, with some variation of included variables depending on the dependent variable. $Z_{t}$ is a vector of global shocks that includes the change in US real interest rate, the world output gap, and relative oil price shocks (measured as the log of the ratio of oil price index to the world's consumer price index). $D_{i}$ is a set of characteristic dummies that includes a dummy for oil exporting countries and regional dummies. Explanatory variables that persistently appear to be statistically insignificant are dropped from the estimation. $\varepsilon_{i t}$ is an i.i.d. error term.

The estimation model is also extended by including a vector, ExtFin ${ }_{i t}$, of external finances, that includes net foreign direct investment (FDI) inflows, net portfolio inflows, net "other" inflows (which mostly include bank lending), short-term debt, and total debt service. For net capital flows, we use the International Financial Statistics (IFS) data and define them as external liabilities (= capital inflows with a positive sign) minus assets (= capital inflows with a negative sign) for each type of flows. Negative values mean that a country experiences a net outflow capital of the type of concern. Short-term debt is included as the ratio of total external debt and total debt service as is that of gross national income $(\mathrm{GNI})$. Both variables are retrieved from the World Development Indicators.

13 Output growth is measured as the 5-year average of the growth rate of per capita real output (using Penn World Table 6.2); output volatility is measured as the 5-year standard deviations of the per capita output growth rate; inflation volatility as the 5-year standard deviations of the monthly rate of inflation; and the medium-term level of inflation as the 5-year average of the monthly rate of inflation.

14 That means that for each dependent variable, three types of regressions, i.e., those with three different combinations of two trilemma variables, are estimated. 
The data set is organized into 5-year panels of 1972-1976, 1977-1981, 1982-1986, 1987-1991, 1992-1996, 1997-2001, 2002-2006. All time-varying variables are included as 5 -year averages. The regression is conducted for the group of less developed countries (LDC) and a subgroup of emerging market economies (EMG). The estimation model for economic growth will be based on the one used in Kose et al. (2009), namely, (OLS) with fixed effects and system (GMM), and the model for output volatility, inflation volatility, and the level of inflation, on Aizenman et al. (2008), i.e., the robust regression model that downweights outliers that can arise in both the dependent variable and explanatory variables such as inflation volatility.

\section{A. Estimation Results of the Basic Models}

\section{Output Growth}

For the estimation, we use a parsimonious model akin to that of Kose et al. (2009), and three estimation methods: pooled OLS, fixed effects (FE) model (with robust standard errors clustered by country) to factor out country-specific effects, and system GMM to control for potential endogeneity. ${ }^{15}$ We test the variables that are often found significant, as mentioned above. ${ }^{16}$ The regression results are reported in Table 1-1 for developing countries and Table 1-2 for emerging market economies, for the three estimation methods.

15 For the fixed-effects estimation, time-fixed effects are also included. The system GMM estimation is conducted using the two-step method and Windmeijer (2005) standard errors with finite-sample correction. We treat initial levels of per capita income, investment ratio, total years of school, and population growth rate as endogenous and instrument using 2 nd lag. Time-fixed effects are also included in the estimation and treated as exogenous instruments.

16 Neither the IR variable nor the interaction terms between trilemma variables and IR are included in the estimation because of the lack of theoretical rationale for the link between IR holding and economic growth. 


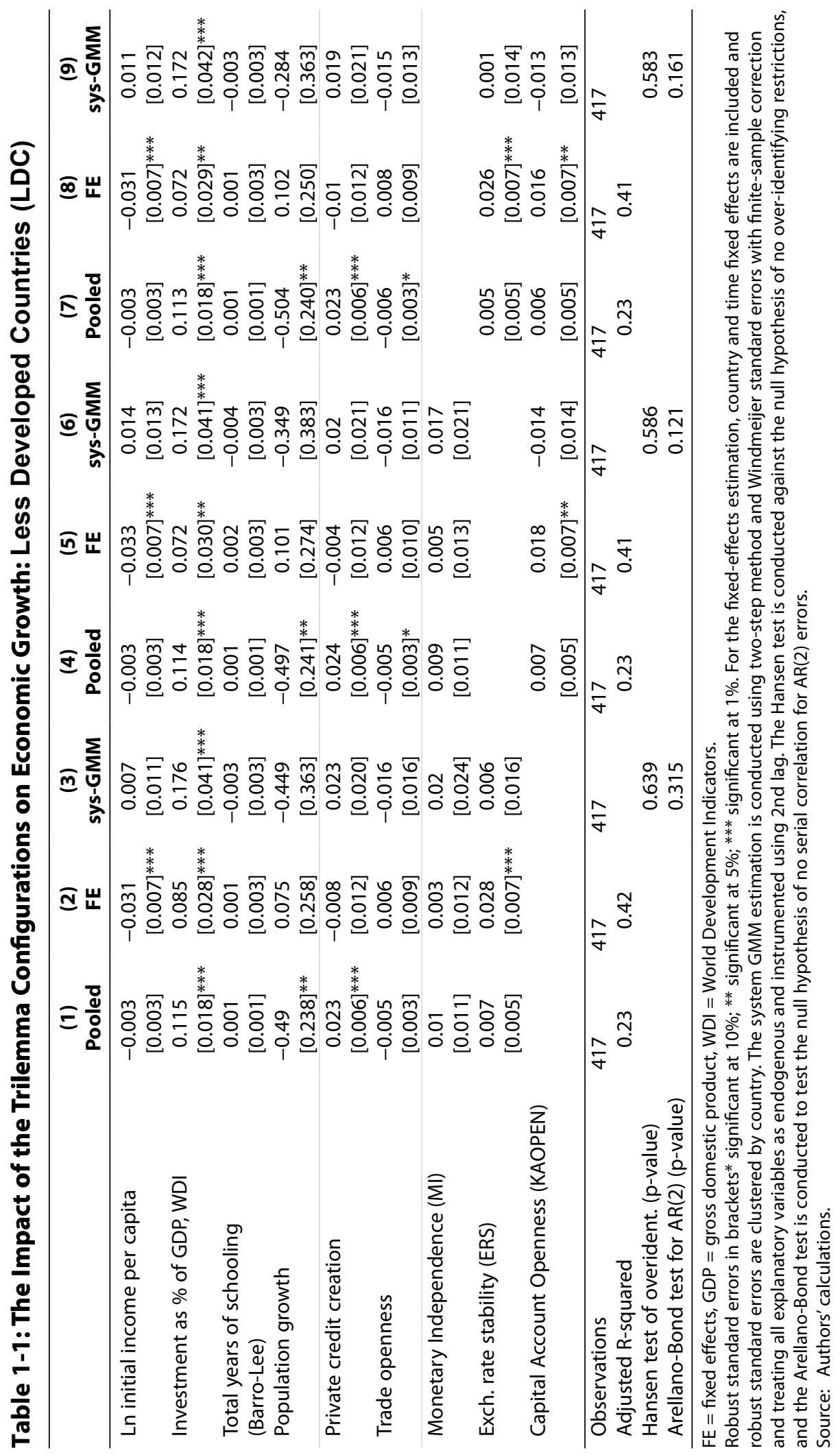




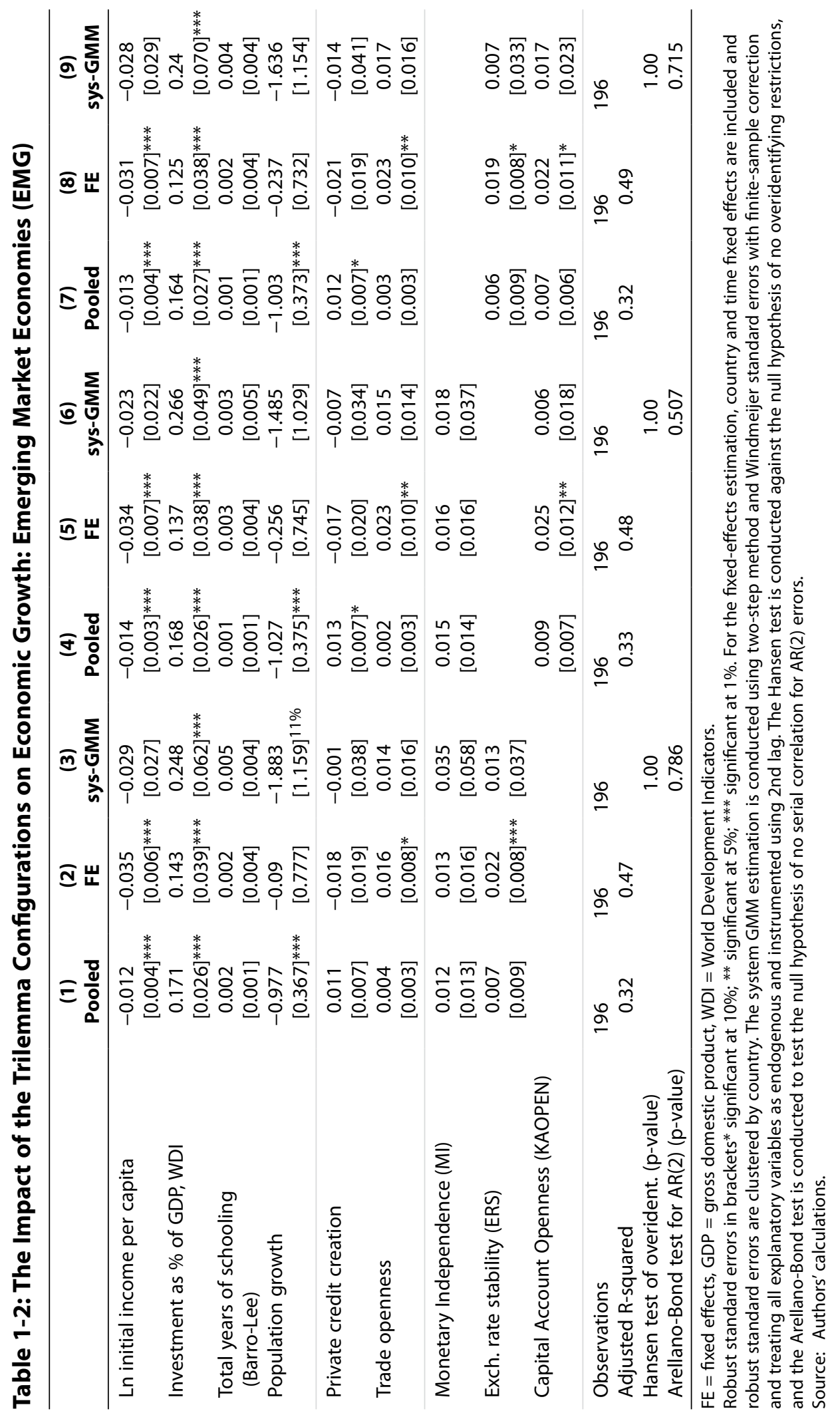


In both Tables 1-1 and 1-2, across different models, the results for the macroeconomic control variables are mostly consistent with the literature. The negative coefficient on the (log of) initial per capita income level evidences the convergence effect (though not found in the GMM estimation). The investment ratio, and population growth to a lesser degree, are positive and negative contributors, respectively, to per capita output growth. Financial development is found to be a positive contributor but only in the OLS estimation. Trade openness has an ambiguous effect; it is a negative factor in the OLS model for the LDC sample whereas it turns to be a positive one for the EMG when the FE model is used.

The trilemma variables enter the estimation relatively weakly, but this is consistent with the ambivalent theoretical predictions of the trilemma policy choices as discussed above. The effect of the trilemma variables is only captured by the FE model for both LDC and EMG sample. Greater exchange rate stability is expected to lead to higher economic growth, a consistent result with Dubas et al. (2005) and De Grauwe and Schnabl (2004). These findings may indicate that exchange rate stability promotes price stability and predictability for investment, thereby lowering the country risk premium and eventually the interest rate. While we must be aware that the FE model fails to incorporate crosssectional variation and that the number of observations for the time dimension is small, these results may capture the effect of policy changes.

Besides the econometric issues, we must also note the possibility that the KAOPEN index may not capture the actual ebb and flow of cross border capital and its impact. Edwards (1999) discusses that the private sector often circumvents capital account restrictions, nullifying the expected effect of regulatory capital controls. More recently, the PRC's de facto openness, despite its de jure closeness, is often the subject of researchers (Aizenman and Glick, 2008, Prasad and Wei, 2007, and Shah and Patnaik, 2009).

Against this backdrop, we augment our estimation model by including de facto measures of capital account openness-measured by net inflows of FDI, portfolio investment, and bank lending-to incorporate the effect of actual external financing. Including these variables may address two important issues with the Asian economies. First, on the de facto basis, Asia is more financially open than what the de jure measures show (Shah and Patnaik, 2009). Hence, it is important to include de facto measures of financial openness while controlling for de jure levels of financial openness. ${ }^{17}$ Second, as Figure 5 shows, Asia is on average a net recipient of FDI, but is a net provider of portfolio investment and bank lending. Hence, using net inflows of different types of capital should add more subtlety to the analysis.

Table 2-1 reports the results for developing countries and Table 2-2 reports the results for emerging market economies from the augmented model that includes the net inflows of FDI, portfolio investment, and "other" investment (which mostly consists of bank lending),

17 We could also argue that while the de jure measures may reflect policy makers' intentions, de facto ones may represent actuality in cross-border capital flows. 
Figure 5: Regional Comparison of Net Capital Inflows
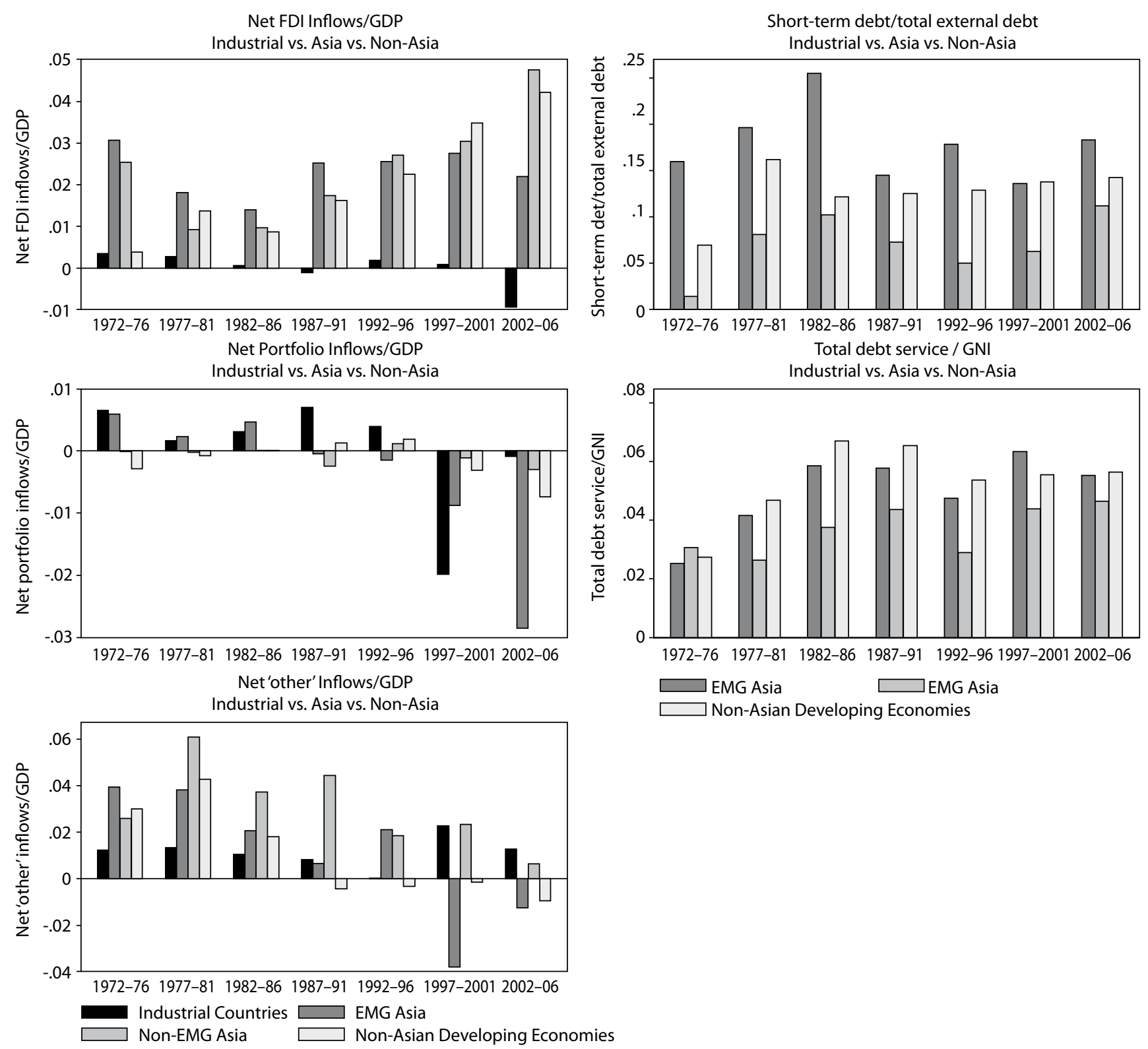

$\mathrm{FDI}=$ foreign direct investment, $\mathrm{EMG}=$ emerging market economies, $\mathrm{GDP}=$ gross domestic product, $\mathrm{GNI}=$ gross national income

short-term debt, and total debt service. To conserve space, the estimation results on the basic macroeconomic control variables are omitted. We also note that this estimation exercise loses many observations especially for economies with medium-income levels, such as Korea and Singapore, because the debt-related variables are not available for developing economies with relatively high income levels. Also, to isolate the effect of external financing from currency crises, we include a dummy for currency crises. ${ }^{18}$

18 The currency crisis dummy variable is derived from the conventional exchange rate market pressure (EMP) index pioneered by Eichengreen et al. (1996). The EMP index is defined as a weighted average of monthly changes in the nominal exchange rate, the percentage loss in international reserves, and the nominal interest rate. The weights are inversely related to the pooled variance of changes in each component over the sample of countries, with an adjustment for countries that experienced hyperinflation following Kaminsky and Reinhart (1999). For countries without the necessary data to compute the EMP index, the currency crisis classifications in Glick and Hutchison (2001) and Kaminsky and Reinhart are used. 


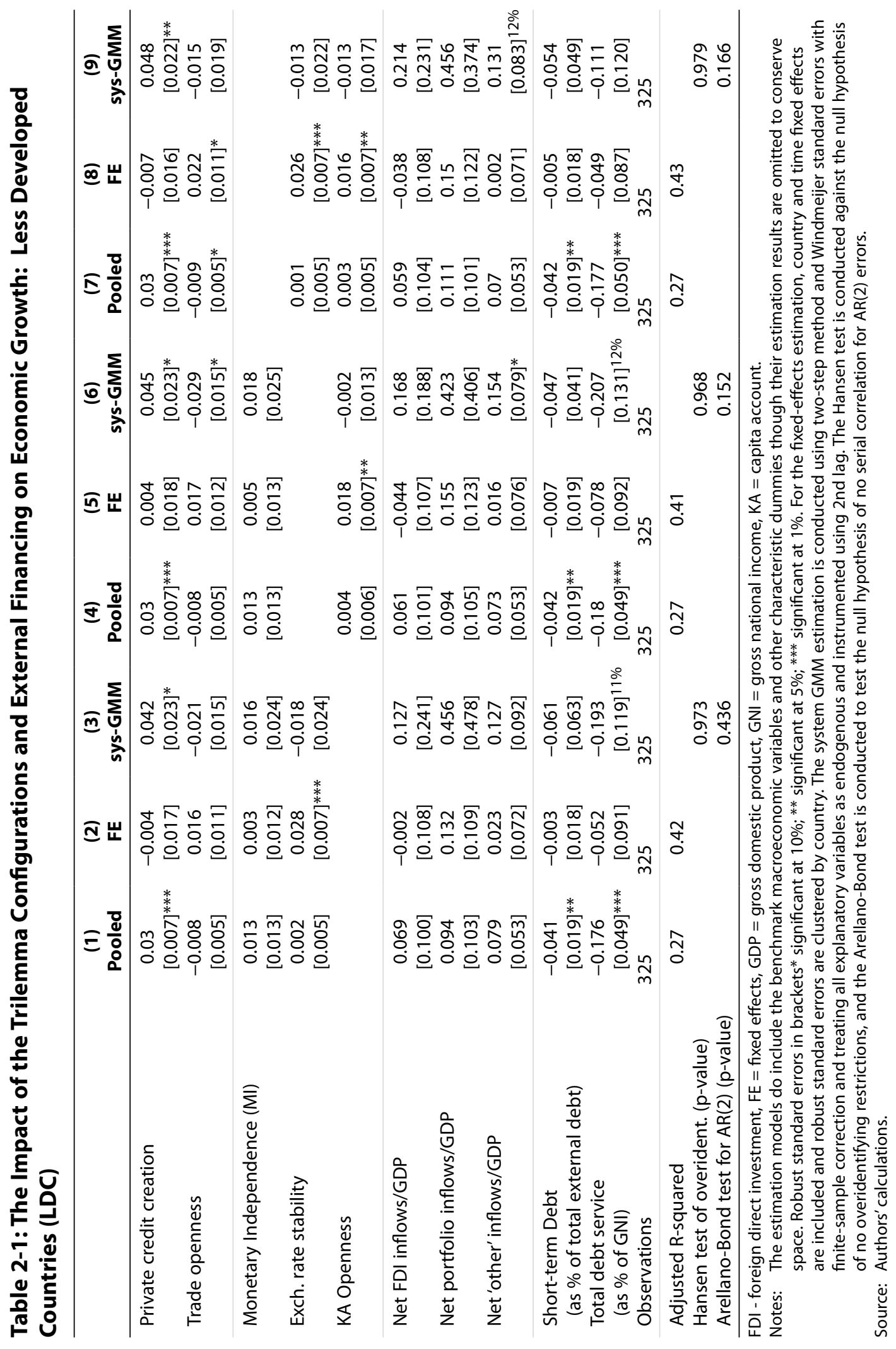




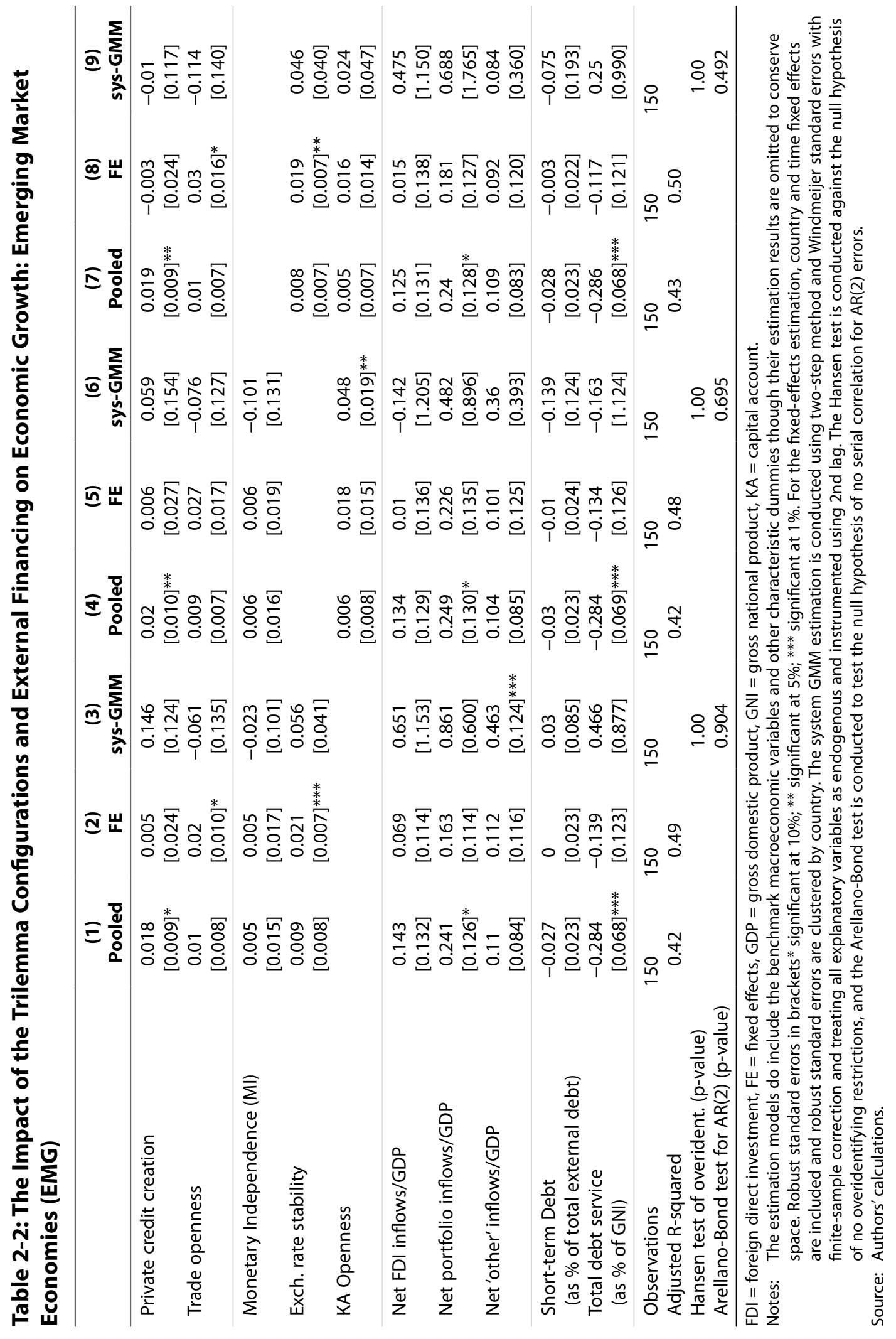


The estimation results for the trilemma variables are mostly intact. Exchange rate stability continues to be a growth enhancer in the FE models of both samples. Financial openness is now found to be a growth enhancer in one of the system-GMM models for EMG. Among the external finance variables, not surprisingly, the variable for total debt services (as percent of $\mathrm{GNI}$ ) is found to hamper output growth, especially for the LDC sample. Short-term debt is also negatively associated with economic growth, but only in the OLS models.

The variables for net capital inflows do not appear to perform well, except for net "other" or bank lending inflows in some of the models. This result has an important implication for Asia because bank lending is the most pervasive form of cross-border capital flow in the region. Our results present some, but weak evidence that cross-border bank lending may have supplemented domestic saving and contributed to economic growth.

\section{Output Volatility}

One of the reasons for the relatively weak results for the trilemma configurations in the growth regression can be because policy arrangements relevant to the trilemma may primarily affect the volatilities in output or inflation, and then indirectly, output growth. Hnatkovska and Loayza (2005) find that macroeconomic volatility and long-run economic growth are negatively related, and that the negative link is considerably larger for the last two decades. ${ }^{19}$ As such, we now investigate the effect of the trilemma configurations on other variables relevant to macroeconomic performances by replacing the dependent variable of equation (1) with the variables for output volatility, inflation volatility, and the level of inflation. The estimation results are shown in Tables 3-1 and 3-2.

19 They also investigate the determinants of the negative link and find that the negative link can be exacerbated by underdevelopment of institutions, intermediate stages of financial development, and inability to conduct countercyclical fiscal policies. 


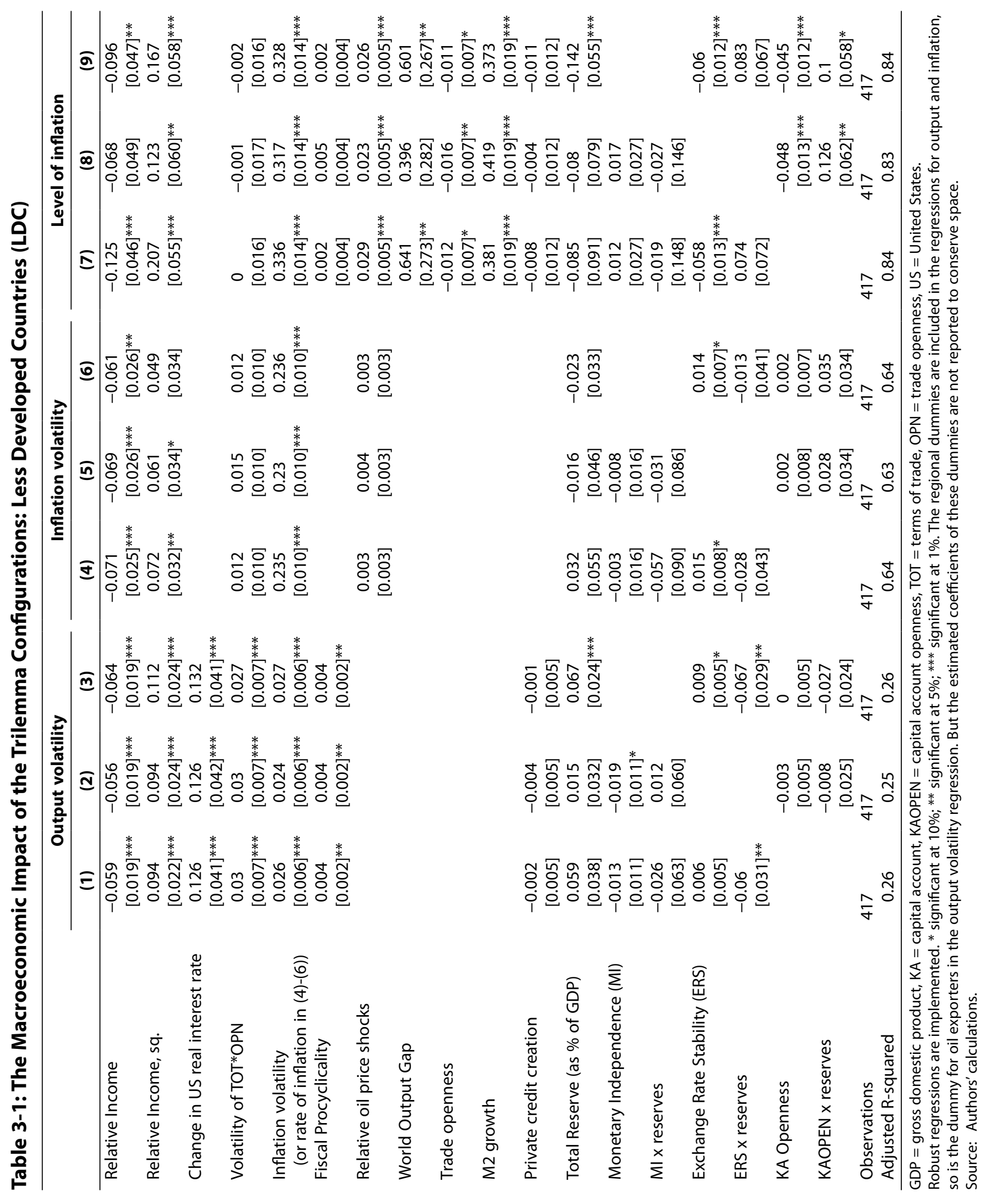




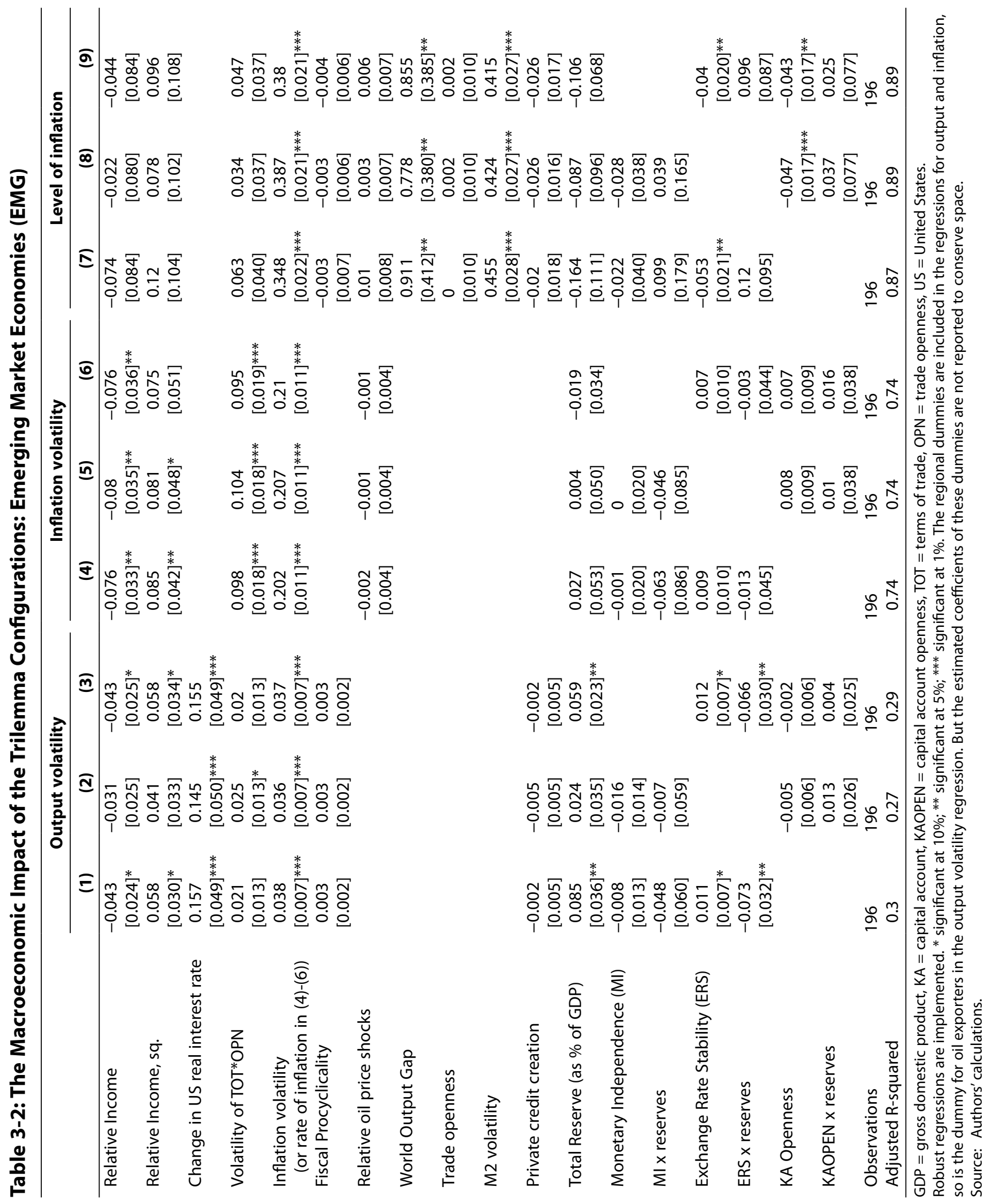


Overall, macroeconomic variables retain the characteristics consistent with what has been found in the literature. In the regression for output volatility (shown in columns (1) through (3) of Tables 3-1 and 3-2), the higher the level of income is (relative to the US), the more reduced output volatility is, though the effect is nonlinear. The bigger change occurs in US real interest rate, the higher output volatility of developing countries may becomeindicating that the US real interest rate may represent the debt payment burden on these countries. The higher TOT shock there is, the higher output volatility countries experience, consistent with Rodrik (1998) and Easterly, et al. (2001) who argue that volatility in world goods through trade openness can raise output volatility. ${ }^{20}$ Countries with procyclical fiscal policy tend to experience more output volatility while countries with more developed financial markets tend to experience lower output volatility though they are not statistically significant. ${ }^{21}$ The results hold qualitatively for the subsample of emerging market economies though the statistical significance tends to appear weaker.

Among the trilemma indexes, monetary independence is found to have a significantly negative effect on output volatility; the greater monetary independence one embraces, the less output volatility the country tends to experience, naturally reflecting the impact of stabilization measures. ${ }^{22}, 23$ Mishkin and Schmidt-Hebbel (2007) find that countries that adopt inflation targeting-one form of increasing monetary independence-are found to reduce output volatility, and that the effect is bigger among emerging market economies. ${ }^{24}$ This volatility-reducing effect of monetary independence may explain the tendency for developing countries, especially non-emerging market ones, to not reduce the extent of monetary independence over years.

Countries with more stable exchange rate tend to experience higher output volatility for both LDC and EMG groups, which conversely implies that countries with more

20 The effect of trade openness is found to have insignificant effects for all subgroups of countries and is therefore dropped from the estimations. This finding reflects the debate in the literature, in which both positive (i.e., volatility enhancing) and negative (i.e., volatility reducing) effects of trade openness has been evidenced. The volatility-enhancing effect in the sense of Easterly et al. (2001) and Rodrik (1998) is captured by the term for (TOT*Trade Openness) volatility. For the volatility reducing effect of trade openness, refer to Calvo et al. (2004), Cavallo (2005, 2007), and Cavallo and Frankel (2004). The impact of trade openness on output volatility also depends on the type of trade, i.e., whether it is inter-industry trade (Krugman, 1993) or intra-industry trade (Razin and Rose, 1994).

21 For theoretical predictions on the effect of financial development, refer to Aghion, et al. (1999) and Caballero and Krishnamurthy (2001). For empirical findings, see Blankenau, et al. (2001) and Kose et al. (2003).

22 Once the interaction term between monetary independence and IR holding is removed from the estimation model, the coefficient of monetary independence becomes significantly negative with the $5 \%$ significance level in model (1) of the LDC sample and in models (1) and (2) of the EMG sample.

23 This finding can be surprising to some if the concept of monetary independence is taken synonymously to central bank independence because many authors, most typically Alesina and Summers (1993), have found more independent central banks would have no or at most, little impact on output variability. However, in this literature, the extent of central bank independence is usually measured by the legal definition of the central bankers and/or the turnover ratios of bank governors, which can bring about different inferences compared to our measure of monetary independence.

24 The link is not always predicted to be negative theoretically. When monetary authorities react to negative supply shocks, that can amplify the shocks and exacerbate output volatility. Cechetti and Ehrmann (1999) find the positive association between adoption of inflation targeting and output volatility. 
flexible exchange rates will experience lower levels of output volatility, as was found in Edwards and Levy-Yeyati (2003) and Haruka (2007). However, the interaction term is found to have a statistically negative effect, suggesting that countries holding high levels of international reserves are able to reduce output volatility. The threshold level of international reserves holding is $13-18 \%$ of GDP. 25 Singapore, a country with a middle level of exchange rate stability (0.50 in 2002-2006) and a very high level of international reserves holding ( $100 \%$ as a ratio of GDP), is able to reduce the output volatility by 2.7 2.9 percentage points. ${ }^{26}$ The $\mathrm{PRC}$, whose exchange rate stability index is as high as 0.97 and whose ratio of reserves holding to GDP is $40 \%$ in $2002-2006$, is able to reduce volatility by 1.4-1.7 percentage points.

When the model is extended to incorporate external finances, whose results are reported in Tables 4-1 and 4-2, generally, the control variables remain qualitatively unchanged, but the trilemma variables slightly increase their statistical significance. Among the trilemma indexes, greater monetary independence continues to be an output volatility reducer. The nonlinear effect of greater exchange rate stability in interaction with IR holding remains, but the threshold level is found to be $12.6 \%$ of GDP in model (3) for developing countries and $18-19 \%$ for emerging market economies.

Countries with more open capital accounts tend to experience lower output volatility according to Table 4-1. However, those with higher IR holding than $23 \%$ of GDP can experience higher volatility by pursuing more financial openness, which is somewhat counterintuitive. 27

25 In Model (3) of Table 3-1, $\check{\alpha}_{1} T L M_{i t}+\check{\alpha}_{3}\left(T L M_{i t} \times I R_{i t}\right)$ for ERS is found to be $0.009 E R S_{i t}-0.067\left(E R S_{i t} \times I R_{i t}\right)$ or $\left(0.009-0.067 I R_{i t}\right) E R S_{i t}$. In order for ERS to have a negative impact, $0.009-0.067 I R_{i t}<0$, and therefore, it must be that $I R_{i t}>0.009 / 0.067=0.13$.

26 See Moreno and Spiegel (1997) for an earlier study of trilemma configurations in Singapore.

27 The result of model (2) in Table 4-1 is consistent with those of models (1) and (3). That is, model (2) predicts that if a country increases its level of monetary independence and financial openness concurrently, it could reduce output volatility. As long as the concept of the trilemma holds true, i.e., the three policy goals are linearly related, as Aizenman et al. (2008) empirically proved, the efforts of increasing both MI and KAOPEN is essentially the same as lowering the level of exchange rate stability. Models (1) and (3) predict that lower ERS leads to lower output volatility. But these models also predict that if the country holds IR more than thresholds, it would have to face higher output volatility, which is found in model (2). 


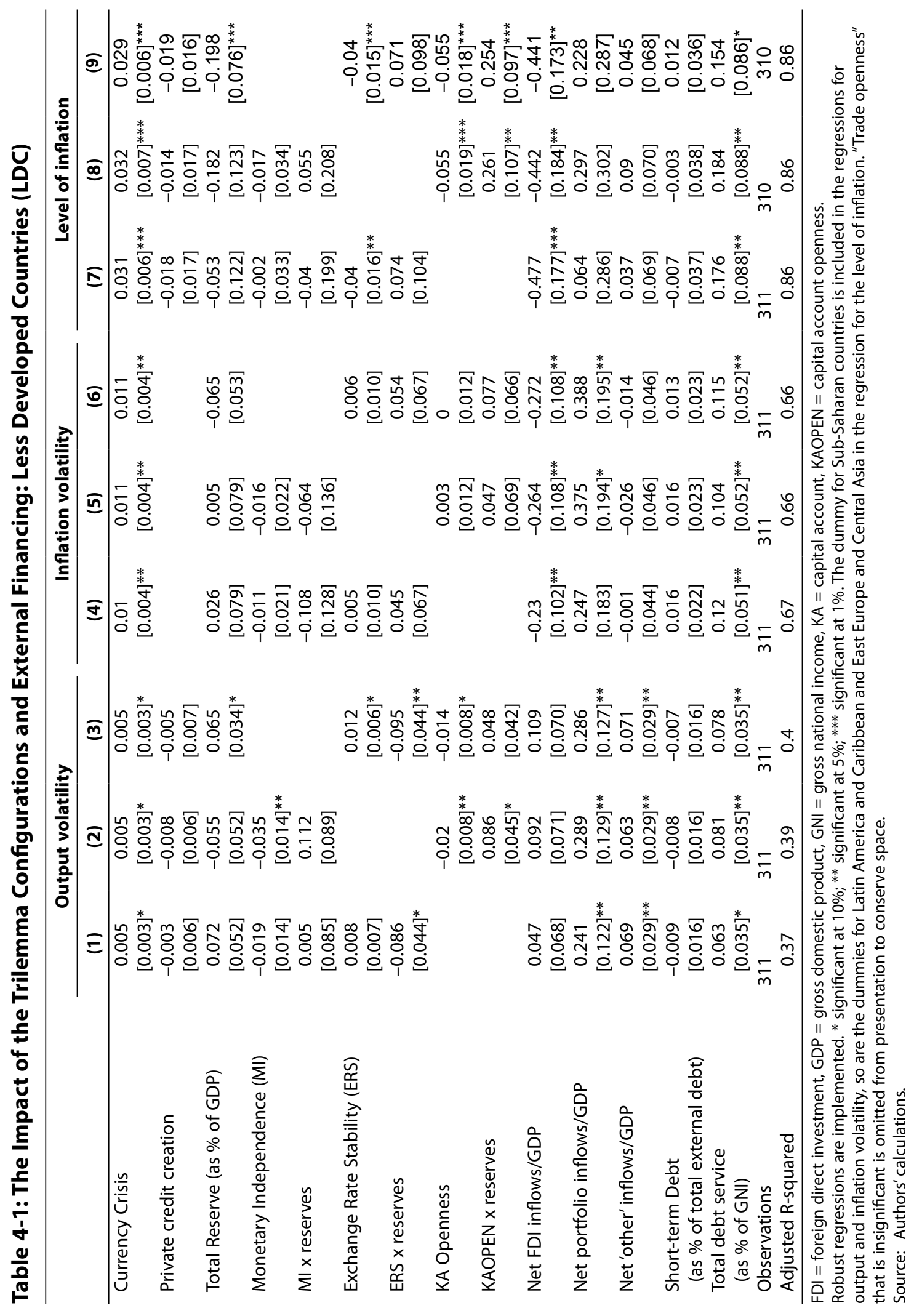




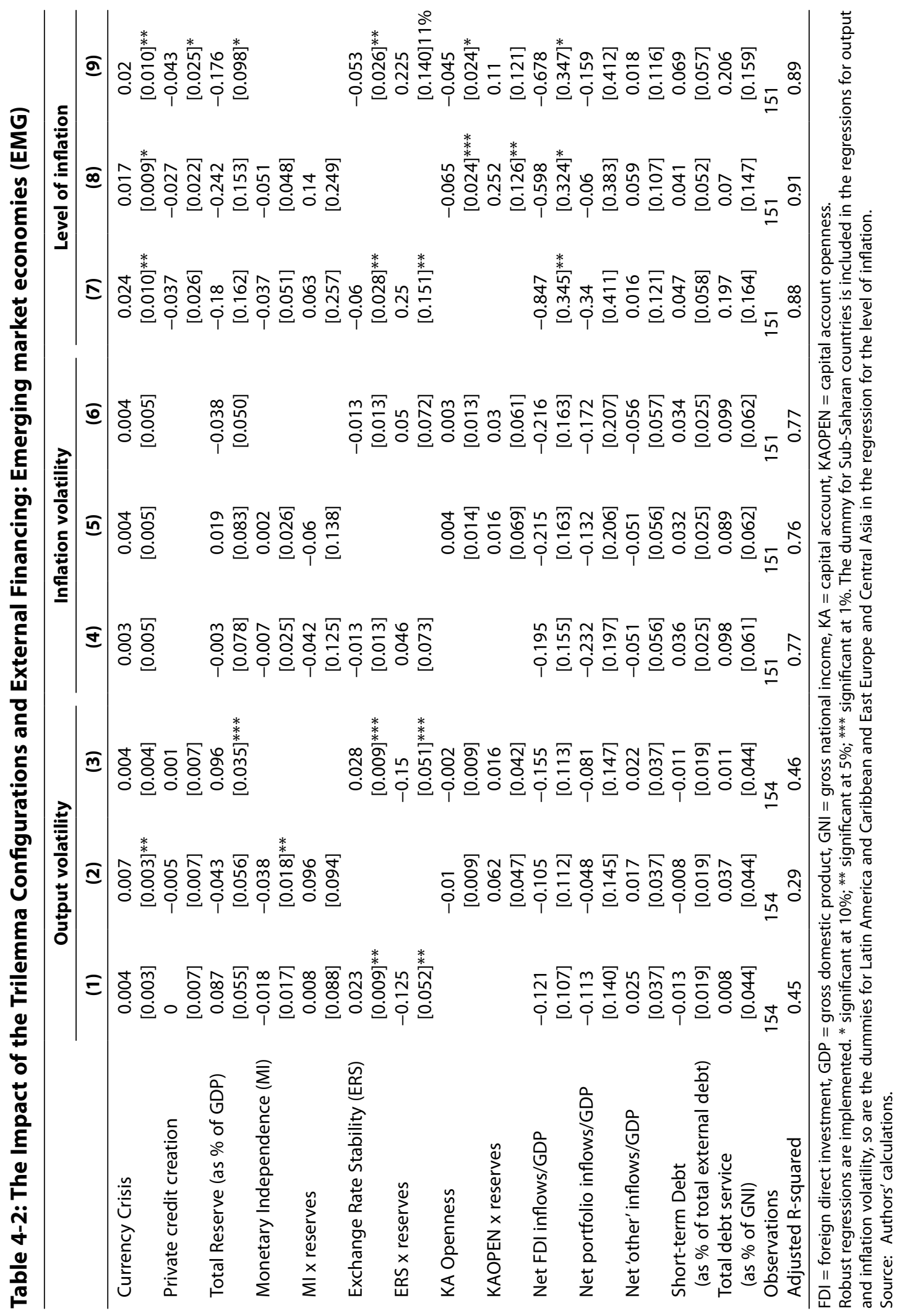


Among the external finance variables, the more "other" capital inflows, i.e., banking lending or more net portfolio inflows, a country receives, the more likely it is to experience higher output volatility, reflecting the fact that countries that experience macroeconomic turmoil often experience an increase in inflows of bank lending or "hot money" such as portfolio investment. Total debt service is found to be a positive contributor to output volatility while short-term debt does not seem to have an effect. These results contrast with the conventional wisdom regarding short-term external debt. ${ }^{28}$

\section{Inflation Volatility}

The regression models for inflation volatility do not turn out to be as significant as those for output volatility, including the performance of the trilemma indexes. The findings on the macro variables are generally consistent with the literature. Countries with higher relative income tend to experience lower inflation volatility, and naturally, those with higher levels of inflation and those that experience currency crises are expected to experience higher inflation volatility. The TOT shock increases inflation volatility, but only for emerging market economies.

The performance of the trilemma indexes appears to be the weakest for this group of estimations. However, exchange rate stability is now a volatility-increasing factor, which is contrary to what has been found in the literature (such as Ghosh, et al., 1997) and somewhat counterintuitive, because countries with more fixity in their exchange rates should experience lower inflation and thereby lower inflation volatility. One possible explanation is that countries with fixed exchange rates tend to lack fiscal discipline and eventually experience devaluation as Tornell and Velasco (2000) argue. ${ }^{29}$ When we include the interaction term between the crisis dummy and the ERS variable to isolate the effect of exchange rate stability for the crisis countries, the estimated coefficient on ERS still remains with the same magnitude and statistical significance.

Even when the model incorporates external finances, the estimation results remain to be weak, except for FDI inflows and total debt service. While FDI inflows are found to be inflation stabilizers, total debt service can be destabilizing inflation, both consistent with the literature.

\section{Medium-Run Level of Inflation}

The models for the medium-run level of inflation fit as well as those for output volatility. Higher inflation volatility, higher M2 growth, and oil price shocks are associated with

28 One might suspect that this result can be driven by multicollinearity between the short-term debt variable and the variables for the various net inflows. However, even when the three net inflow variables are removed from the models, still the total debt service continues to be a positive factor while the short-term debt variable continues to be an insignificant one.

29 Tornell and Velasco argue that while countries with flexible exchange rates face the cost of having lax fiscal policy immediately, countries with fixed exchange rates tend to lack fiscal discipline because "under fixed rates bad behavior today leads to punishment tomorrow." 
higher inflation. Also, when the world economy is experiencing a boom, developing countries tend to experience higher inflation, which presumably reflects strong demand for goods produced and exported by developing countries.

Among the trilemma variables, greater exchange rate stability leads to lower inflation for both developing and emerging market economies, a result consistent with the literature (such as Ghosh et al., 1997). This finding and the previously found positive association between exchange rate stability and output volatility are in line with the theoretical prediction that establishing stable exchange rates is a trade-off issue for policy makers; it will help the country to achieve lower inflation by showing a higher level of credibility and commitment, but at the same time, the efforts of maintaining stable exchange rates will rid policy makers of an important adjustment mechanism through fluctuating exchange rates.

The estimations for both subsamples show that the more financially open a developing country is, the lower inflation it will experience. Interestingly, the more open to trade a country is, the more likely it is to experience lower inflation for the LDC regressions.

The negative association between "openness" and inflation has been the subject of debate as globalization has proceeded. ${ }^{30}$ Romer (1993), extending the Barro-Gordon (1983) model, verified that the more open to trade a country becomes, the less motivated its monetary authorities are to inflate, suggesting a negative link between trade openness and inflation. Razin and Binyamini (2007) predicted that both trade and financial liberalization will flatten the Phillips curve, so that policy makers will become less responsive to output gaps and more aggressive in fighting inflation. ${ }^{31}$ Here, across different subsamples of developing countries, we present evidence consistent with the negative openness-inflation relationship.

The extended version of the regressions that incorporate external finances generally retain the same characteristics. But for emerging market economies, the interaction term between ERS and international reserves holding is found to have a positive impact on the rate of inflation. Models (8) and (9) in Table 4-2 show that if the ratio of reserves holding to GDP is greater than about $24 \%$, the efforts of pursuing exchange rate stability can help increase the level of inflation. This means that countries with excess levels of reserves holding will eventually face the limit in the efforts of fully sterilizing foreign exchange intervention to maintain exchange rate stability - thereby experiencing higher inflation. In the LDC sample (Table 4-1), we can find the same kind of threshold in models (8) and (9); financial openness can lead to lower inflation, but only up to the case when IR hold is below $21-22 \%$ as a ratio to GDP. Considering that only in a financially open economy do monetary authorities face the need for foreign exchange interventions, the threshold of IR holding for financial openness can be interpreted in the same way as that for exchange

30 Rogoff (2003) argues that globalization contributes to dwindling mark-ups, and therefore, disinflation.

31 Loungani et al. (2001) provides empirical evidence that countries with greater restrictions on capital mobility face steeper Phillips curves. 
rate stability. This means that there are limits to sterilized interventions, and that it is more binding for financially open economies. Aizenman and Glick (2008) and Glick and Hutchison (2008) show that the PRC has started facing more inflationary pressure in 2007 when allegedly intervening the foreign exchange market intensively to sustain exchange rate stability. This finding indicates that sterilized interventions would eventually lead to a rise in expected inflation if they are conducted as an effort to maintain monetary independence and exchange rate stability while having somewhat open financial markets. The rise in the inflationary pressure provides evidence that policy makers cannot evade the constraint of the trilemma.

Lastly, among the external finances variables, FDI is found to be an inflation reducer. One possible explanation is that countries tend to stabilize inflation movement to attract FDI. Lastly, and unsurprisingly, higher levels of total debt services are found to help increase inflation for the LDC sample.

\section{B. Implications for Asia}

In the growth regressions, we learned that investment ratios, exchange rate stability, financial openness, bank lending inflows, and low levels of total debt services are the positive contributors to economic growth among developing countries. How do these variables behave for the Asian economies? In Figure 4, we have seen that Asia on average maintained the medium level of exchange rate stability, but that its level is not as high as that of other non-Asian developing countries. Asian economies, especially those with emerging markets, have achieved the medium level of financial openness since the 1980s, but have not experienced rapid financial liberalization as Latin American emerging market economies have done. Figure 5 reports that Asian emerging market economies are currently net recipients of FDI and net providers of portfolio and bank lending after the Asian crisis. Before the crisis, however, both emerging and non-emerging Asian economies were more dependent on bank lending than FDI. ${ }^{32}$ Both short-term debt as a ratio to total external debt and total debt service as a ratio to GNI have stayed at relatively high levels for this group of economies. ${ }^{33}$ Given these observations, the drive for high economic growth among Asian emerging market economies can be narrowed down to high investment ratios and high levels of bank lending inflows. Especially with respect to the link between Asia and globalization, as many researcher have discussed, one of the keys to economic success is the high level of openness to bank lending, which may have had a synergistic relationship with domestic investment.

The estimation results on the determinants of output volatility also provide some interesting insights on Asian economic development. The finding that countries can reverse the volatility-increasing effect of greater exchange rate stability by holding higher

32 It must be noted that the scales are different among different panels of figures in Figure 5.

33 We must remind that the debt data are not available for emerging market economies with relatively high income levels such as Hong Kong, Korea, and Singapore. 
levels of IR than some threshold (about 13-18\% of GDP) may explain the reason why many Asian developing countries hold higher levels of IR. Unraveling the motive for IR holding also has an important implication for the current global crisis. Some economists argue that the efforts made by Asian economies to hold IR in an attempt to stabilize their exchange rates could have expanded liquidity rapidly in global capital markets and contributed to finance profligacy in the advanced countries including the housing bubble in the US. Hence, we do need to shed further light on how IR holding and the exchange rate regime interact with each other.

Figure 6 shows the marginal interactive effects between ERS and IR based on the estimates from Column 3 of Table 3-2. For presentation purposes, the EMG group of countries is divided into three subgroups: (i) an Asian group, (ii) a Latin American group, and (iii) all other EMG countries. In all the panels of figures, the contours are drawn to present different levels of the effect of ERS on output volatility conditional on the level of IR. The solid horizontal line refers to the threshold of IR at $18 \%$ of GDP, above which higher levels of ERS has a negative impact on output volatility. ${ }^{34}$ For example, the solid contour line above the threshold shows the combinations of ERS and IR that lead to a one percentage point reduction in output volatility. In the figure, the further toward the northeast corner in the panel, i.e., the higher level of ERS and IR a country pursues, the more negative the impact on output volatility. Below the threshold, however, it is true that the further toward the southeast corner, i.e., the higher level of ERS and the lower level of IR a country pursues, the more positive the impact on output volatility. In each of the panels, the scatter diagrams of ERS and IR are superimposed. The black circles indicate ERS and IR for 2002-2006 and the red "x's" for 1992-1996. ${ }^{35}$

34 In Model (3) in Table 3-2, $\check{\alpha}_{1} T L M_{i t}+\breve{\alpha}_{3}\left(T L M_{i t} \times I R_{i t}\right)$ for ERS is found to be $0.012 E R S_{i t}-0.066\left(E R S_{i t} \times I R_{i t}\right)$. If the marginal effect is $-1 \%$, it must be that $-0.01=0.012 E R S_{i t}-0.066\left(E R S_{i t} \times I R_{i t}\right)$. If we solve this for $I R$, then we obtain $I R_{i t}=\frac{0.012}{0.066}-\frac{-0.01}{0.066 E R S_{i t}}$. We repeat this calculation for the $-2 \%$ impact, $-3 \%$ impact, etc., to create the other contours.

35 The estimated coefficient on IR (level) is significantly positive in Column (1) of Table 3-2, which indicates the volatility-enhancing effect of IR itself. Hence, it is essentially a trade-off between holding more IR and pursuing greater exchange rate stability once the level of IR surpasses the threshold level. The analysis presented in Figure 6 focuses on the marginal effect of ERS and how it changes depending on the level of IR while keeping in mind that higher levels of IR is volatility-increasing. 


\section{Figure 6: Interactive Effects of Exchange Rate Stability and IR Holding}

(a) Asian EMGs

1992-96 (red-x) vs. 2002-06 (black circle)

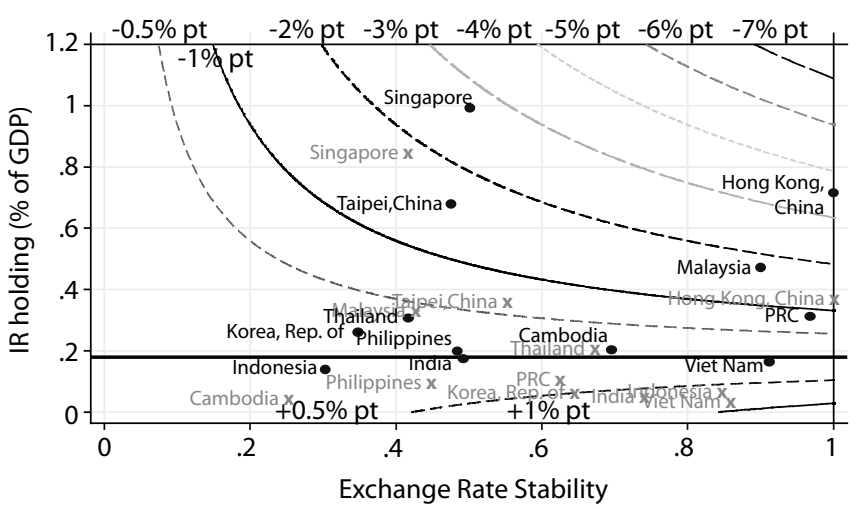

(c) Other EMGs

1992-96 (red-x) vs. 2002-06 (black circle)

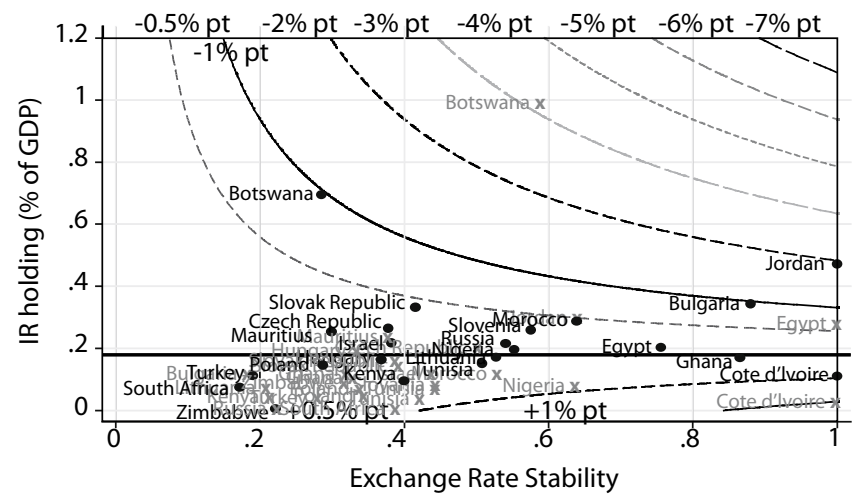

(b) Latin American EMGs

1992-96 (red-x) vs. 2002-06 (black circle)

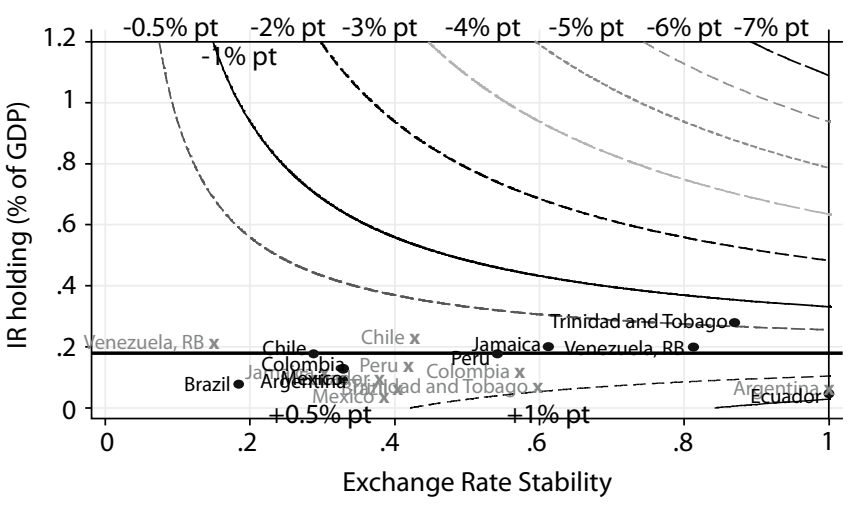

$\mathrm{GDP}=$ gross domestic product, $\mathrm{EMG}=$ emerging market economies, $\mathrm{IR}=$ international reserves.

These diagrams highlight several interesting observations. First, from the 1992 to 1996 and 2002 to 2006 periods, periods that encompass the last wave of global crises whose epicenter was in Asia, many countries, especially those in East Asia and Eastern Europe, increased their IR holding above the threshold. Second, the movement is not necessarily toward the northeast direction. Rather, it is around the threshold level where the effect of ERS is neutral (i.e., zero percentage point impact), unless they move much higher toward output volatility-reducing territory (such as Bulgaria and the PRC). Last, only a handful of economies have achieved combinations of ERS and IR that significantly reduce output volatility. Such economies include Botswana; PRC; Hong Kong, China; Malaysia; Jordan; and Singapore. However, the fact that three Asian economies are among the countries with large IR holding and great ERS may explain why Asian economies are often perceived to be currency manipulators although they are more of exceptions than the rule. 


\section{Further Investigation into Output Volatility and Trilemma Choices}

\section{A. Channels to Output Volatility}

Given the current state of the world economy, one cannot help but focus on the estimation results for output volatility. One natural question that arises is through what channels do these factors contribute to output volatility. To answer this question, we estimate similar models for output volatility but replace the dependent variable with real exchange rate stability, through which net exports can be affected, and the volatility of investment. This exercise should help us examine whether and to what extent policy choices can differ depending on the extent of economic openness.

\section{Results on Investment Volatility and Real Exchange Rate Volatility}

The results shown in columns (1) through (3) of Table 5 correspond to investment volatility and those (4) through (6) of Table 5 correspond to real exchange rate stability specifications. However, for the estimation of the real exchange rate stability, some of the explanatory variables are changed; the variables for the change in the US real interest rate, fiscal procyclicality, and financial development (measured by private credit creation as a ratio to GDP) are dropped from the estimation, and replaced with inflation volatility, and differentials in inflation volatility between the home and base countries are included instead. ${ }^{36}$

By comparing the results of these different specifications with dependent variables, we can make some interesting observations. First, we can also observe the negative effect of monetary independence on the investment volatility estimation as we did in that on output volatility. However, if the level of IR holding is above $15-20 \%$ of GDP, higher monetary independence could lead to higher volatility in investment. This may be because higher levels of international reserves could lead to higher levels of liquidity, thus to more volatile movement in the cost of capital. Second, while a higher degree of exchange rate stability could (unsurprisingly) induce greater real exchange rate stability, it could also lead to more volatile investment. But as was the case with output volatility, if the level of IR holding exceeds a given threshold, greater exchange rate stability reduces investment volatility. ${ }^{37}$ Third, financial openness has a negative impact on both real exchange rate stability and investment volatility. Hence, we can conclude that financial liberalization could help reduce output volatility by making both real exchange rate and investment more stable. Last, the investment volatility regressions show that net portfolio and bank lending inflows can be volatility-increasing, although banking lending inflows can reduce real exchange rate volatility.

36 Interest rate differentials are also tested, but did not turn out to be significant. Therefore, they are not included in the estimation.

37 The threshold levels of IR holding are $18 \%$ of GDP in model (1) and 28\% of GDP in model (3) in Table 5-1. In Table $5-2$, they are $14 \%$ in model (1) and $26 \%$ in model (3). 
Table 5-1: Determinants of Output Volatility: Less Developed Countries (LDC)

\begin{tabular}{|c|c|c|c|c|c|c|}
\hline & \multicolumn{3}{|c|}{ Investment Volatility } & \multicolumn{3}{|c|}{ Real Exchange Rate Volatility } \\
\hline & (1) & (2) & (3) & (4) & (5) & (6) \\
\hline Relative Income & $\begin{array}{l}-0.1 \\
{[0.143]}\end{array}$ & $\begin{array}{l}-0.15 \\
{[0.142]}\end{array}$ & $\begin{array}{c}-0.125 \\
{[0.139]}\end{array}$ & $\begin{array}{c}-0.016 \\
{[0.020]}\end{array}$ & $\begin{array}{c}0.027 \\
{[0.031]}\end{array}$ & $\begin{array}{c}-0.015 \\
{[0.020]}\end{array}$ \\
\hline Relative Income, sq. & $\begin{array}{c}0.121 \\
{[0.264]}\end{array}$ & $\begin{array}{c}0.239 \\
{[0.265]}\end{array}$ & $\begin{array}{c}0.211 \\
{[0.258]}\end{array}$ & $\begin{array}{c}0.017 \\
{[0.037]}\end{array}$ & $\begin{array}{c}-0.041 \\
{[0.057]}\end{array}$ & $\begin{array}{c}0.019 \\
{[0.038]}\end{array}$ \\
\hline $\begin{array}{l}\text { Change in US real interest } \\
\text { rate }\end{array}$ & $\begin{array}{c}0.39 \\
{[0.199]^{*}}\end{array}$ & $\begin{array}{c}0.306 \\
{[0.198]}\end{array}$ & $\begin{array}{c}0.259 \\
{[0.194]}\end{array}$ & & & \\
\hline Volatility of TOT*OPN & $\begin{array}{l}0.095 \\
{[0.036]^{* * *}}\end{array}$ & $\begin{array}{l}0.121 \\
{[0.036]^{* * *}}\end{array}$ & $\begin{array}{l}0.103 \\
{[0.035]^{* * * *}}\end{array}$ & $\begin{array}{c}0.008 \\
{[0.005]}\end{array}$ & $\begin{array}{c}0.011 \\
{[0.008]}\end{array}$ & $\begin{array}{c}0.008 \\
{[0.005]}\end{array}$ \\
\hline $\begin{array}{l}\text { Inflation volatility } \\
\text { (Infl. vol. differentials in } \\
\text { (4)-(6)) }\end{array}$ & $\begin{array}{l}0.134 \\
{[0.025]^{* * *}}\end{array}$ & $\begin{array}{l}0.133 \\
{[0.025]^{* * *}}\end{array}$ & {$[0.131$} & $\begin{array}{l}0.038 \\
{[0.003]^{* * *}}\end{array}$ & {$[0.005]^{* * *}$} & $\begin{array}{l}0.038 \\
{[0.004]^{* * *}}\end{array}$ \\
\hline Fiscal Procyclicality & $\begin{array}{l}-0.001 \\
{[0.009]}\end{array}$ & $\begin{array}{l}0.003 \\
{[0.009]}\end{array}$ & $\begin{array}{c}0.004 \\
{[0.009]}\end{array}$ & & & \\
\hline Trade openness & & & & $\begin{array}{l}-0.005 \\
{[0.003]^{*}}\end{array}$ & $\begin{array}{l}-0.011 \\
{[0.004]^{* * *}}\end{array}$ & $\begin{array}{c}-0.005 \\
{[0.003]^{*}}\end{array}$ \\
\hline Currency Crisis & $\begin{array}{l}0.01 \\
{[0.011]}\end{array}$ & $\begin{array}{c}0.002 \\
{[0.011]}\end{array}$ & $\begin{array}{c}0.007 \\
{[0.011]}\end{array}$ & $\begin{array}{l}0.009 \\
{[0.002]^{* * *}}\end{array}$ & $\begin{array}{l}0.013 \\
{[0.002]^{* * *}}\end{array}$ & $\begin{array}{l}0.009 \\
{[0.002]^{* * *}}\end{array}$ \\
\hline Private credit creation & $\begin{array}{c}-0.011 \\
{[0.026]}\end{array}$ & $\begin{array}{c}-0.012 \\
{[0.026]}\end{array}$ & $\begin{array}{c}-0.001 \\
{[0.025]}\end{array}$ & & & \\
\hline Total Reserve (as \% of GDP) & $\begin{array}{c}-0.229 \\
{[0.210]}\end{array}$ & $\begin{array}{c}-0.393 \\
{[0.205]^{*}}\end{array}$ & $\begin{array}{c}0.158 \\
{[0.132]}\end{array}$ & $\begin{array}{c}0.022 \\
{[0.030]}\end{array}$ & $\begin{array}{c}0.038 \\
{[0.045]}\end{array}$ & $\begin{array}{c}-0.013 \\
{[0.019]}\end{array}$ \\
\hline Monetary Independence (MI) & $\begin{array}{l}-0.181 \\
{[0.056]^{* * *}}\end{array}$ & $\begin{array}{l}-0.159 \\
{[0.057]^{* * *}}\end{array}$ & & $\begin{array}{c}0.004 \\
{[0.008]}\end{array}$ & $\begin{array}{l}0.024 \\
{[0.012]^{* *}}\end{array}$ & \\
\hline MI $x$ reserves & $\begin{array}{l}1.193 \\
{[0.342]^{* * *}}\end{array}$ & $\begin{array}{l}0.785 \\
{[0.351]^{* *}}\end{array}$ & & $\begin{array}{c}-0.049 \\
{[0.048]}\end{array}$ & $\begin{array}{l}-0.086 \\
{[0.076]}\end{array}$ & \\
\hline Exchange Rate Stability (ERS) & $\begin{array}{l}0.077 \\
{[0.026]^{* * *}}\end{array}$ & & $\begin{array}{l}0.07 \\
{[0.025]^{* * *}}\end{array}$ & $\begin{array}{l}-0.037 \\
{[0.004]^{* * *}}\end{array}$ & & $\begin{array}{l}-0.038 \\
{[0.004]^{* * *}}\end{array}$ \\
\hline ERS $x$ reserves & $\begin{array}{l}-0.413 \\
{[0.179]^{* *}}\end{array}$ & & $\begin{array}{c}-0.254 \\
{[0.170]}\end{array}$ & $\begin{array}{c}-0.007 \\
{[0.025]}\end{array}$ & & $\begin{array}{c}0.001 \\
{[0.024]}\end{array}$ \\
\hline KA Openness & & $\begin{array}{c}-0.042 \\
{[0.032]}\end{array}$ & $\begin{array}{c}-0.012 \\
{[0.030]}\end{array}$ & & $\begin{array}{r}-0.008 \\
{[0.007]}\end{array}$ & $\begin{array}{c}-0.004 \\
{[0.004]}\end{array}$ \\
\hline KAOPEN $x$ reserves & & $\begin{array}{c}0.223 \\
{[0.178]}\end{array}$ & $\begin{array}{c}0.051 \\
{[0.165]}\end{array}$ & & $\begin{array}{c}0.029 \\
{[0.038]}\end{array}$ & $\begin{array}{c}0.019 \\
{[0.024]}\end{array}$ \\
\hline Net FDI inflows/GDP & $\begin{array}{c}0.327 \\
{[0.274]}\end{array}$ & $\begin{array}{c}0.347 \\
{[0.280]}\end{array}$ & $\begin{array}{c}0.25 \\
{[0.272]}\end{array}$ & $\begin{array}{c}-0.041 \\
{[0.041]}\end{array}$ & $\begin{array}{c}-0.088 \\
{[0.064]}\end{array}$ & $\begin{array}{c}-0.033 \\
{[0.042]}\end{array}$ \\
\hline Net portfolio inflows/GDP & $\begin{array}{l}1.48 \\
{[0.493]^{* * *}}\end{array}$ & $\begin{array}{l}1.414 \\
{[0.508]^{* * *}}\end{array}$ & $\begin{array}{l}1.364 \\
{[0.494]^{* * *}}\end{array}$ & $\begin{array}{c}0.052 \\
{[0.069]}\end{array}$ & $\begin{array}{c}0.046 \\
{[0.108]}\end{array}$ & $\begin{array}{c}0.054 \\
{[0.071]}\end{array}$ \\
\hline Net 'other' inflows/GDP & $\begin{array}{l}0.376 \\
{[0.116]^{* * * *}}\end{array}$ & $\begin{array}{l}0.38 \\
{[0.116]^{* * *}}\end{array}$ & $\begin{array}{l}0.418 \\
{[0.112]^{* * * *}}\end{array}$ & $\begin{array}{c}-0.028 \\
{[0.016]^{*}}\end{array}$ & $\begin{array}{c}-0.014 \\
{[0.025]}\end{array}$ & $\begin{array}{c}-0.028 \\
{[0.016]^{*}}\end{array}$ \\
\hline $\begin{array}{l}\text { Short-term Debt } \\
\text { (as \% of total external debt) }\end{array}$ & $\begin{array}{l}-0.042 \\
{[0.063]}\end{array}$ & $\begin{array}{c}-0.042 \\
{[0.063]}\end{array}$ & $\begin{array}{l}-0.042 \\
{[0.062]}\end{array}$ & $\begin{array}{c}0.006 \\
{[0.008]}\end{array}$ & $\begin{array}{c}0.004 \\
{[0.013]}\end{array}$ & $\begin{array}{c}0.007 \\
{[0.008]}\end{array}$ \\
\hline $\begin{array}{l}\text { Total debt service } \\
\text { (as \% of GNI) }\end{array}$ & $\begin{array}{c}0.264 \\
{[0.140]^{*}}\end{array}$ & $\begin{array}{c}0.232 \\
{[0.138]^{*}}\end{array}$ & $\begin{array}{c}0.213 \\
{[0.136]}\end{array}$ & $\begin{array}{c}0.02 \\
{[0.020]}\end{array}$ & $\begin{array}{l}0.081 \\
{[0.031]^{* * *}}\end{array}$ & $\begin{array}{l}0.02 \\
{[0.021]}\end{array}$ \\
\hline Observations & 309 & 309 & 309 & 310 & 310 & 310 \\
\hline Adjusted R-squared & 0.31 & 0.26 & 0.25 & 0.63 & 0.29 & 0.63 \\
\hline
\end{tabular}

$\mathrm{GDP}=$ gross domestic product, $\mathrm{GNI}=$ gross national income, $\mathrm{KA}=$ capital account, $\mathrm{KAOPEN}=$ capital account openness, TOT $=$ terms of trade, US = United States.

Robust regressions are implemented. ${ }^{*}$ significant at $10 \% ;{ }^{* *}$ significant at $5 \%$; ${ }^{* *}$ significant at $1 \%$. The dummy for Sub-Saharan countries is included in the regressions for output and inflation volatility, so are the dummies for Latin America and Caribbean and East Europe and Central Asia in the regression for the level of inflation.

Source: Authors' calculations. 


\section{Results on Other Aspects of Macroeconomic Performance}

Additionally, we repeat the same exercise for additional variables pertaining to other aspects of macroeconomic performance, namely, the volatility of final consumption-the sum of private consumption and government expenditure, the volatility of GNI, and the ratio of the two variables. The motivation for these estimations is twofold. First, we need to ensure if there are channels other than investment and net exports through which the trilemma policy configurations can affect output volatility. Second, the ratio of the volatility of GNI to that of final consumption is essentially a proxy to the measure of risk sharing. In other words, a higher value of the ratio means a smaller volatility of final consumption compared to that of $\mathrm{GNI}$, which can arise when economic agents successfully diversify risk and smooth consumption. Hence, if trilemma policy choices are found to reduce the ratio, that can be interpreted as evidence for successful international risk sharing. ${ }^{38}$

The regression results for final consumption volatility are not robust in terms of not only the macroeconomic control variables, but also of the trilemma variables (not reported). Although the weak estimation results may indicate a possibility of misspecification in these regressions, this finding suggests at least that the channel of final consumption can be ruled out; it is either investment or net exports through which trilemma configurations affect output volatility.

While the estimation results for $\mathrm{GNI}$ are found to be quite similar to the estimation of output volatility, the estimation on the ratio of GNI volatility to final consumption volatility do not perform well at all. Considering that home bias is much more pervasive in developing countries, the insignificant results are not surprising. Developing countries are not reaping the benefits of international risk sharing, though that could also mean that there is room for these countries to reap the benefit from financial liberalization.

\section{Policy Implications and Asia}

In the previous exercise, we found different dynamics between the investment volatility model and the model on real exchange rate volatility. This difference should suggest that the effect of international macroeconomic policy configurations differ depending upon how much weight policy makers place between these two policy goals. For example, if policy makers put greater weight on real exchange rate stability, it is better to pursue more exchange rate stability and greater financial openness (which implies lower levels of monetary independence), which could have a volatility-enhancing impact on investment and output, although the answer depends on the level of IR holding. More concretely, the results from model (1) in Table 5-2 show that greater (weaker) monetary independence increase (decrease) real exchange rate volatility. The estimation results also indicate

38 However, plotting the time series of the ratio of final consumption volatility to GNI volatility is not promising. While the ratio appears to be trending up moderately among industrialized countries, i.e., they are reaping the benefits of diversifying risk and smoothing consumption, there is no discernable trend for the group of developing economies. 
that the threshold of IR holding level (as a ratio to GDP) for greater (weaker) monetary independence to have a positive (negative) effect on investment volatility is $15 \%$ of GDP, whereas that for greater (weaker) exchange rate stability to have a negative (positive) effect is $16 \%$. Hence, if an emerging market country holds a higher level of IR higher than $16 \%$ and tries to pursue a higher level of exchange rate stability and a lower level monetary independence (i.e., a combination of greater exchange rate stability and greater financial openness), that country could achieve lower levels of not only real exchange rate stability, but also investment. This result may explain why many emerging market economies-especially those that are more open to international trade such as Asian emerging market economies - tend to prefer exchange rate stability and holding a massive amount of IR while pursuing financial liberalization.

This finding is significantly relevant to Asian economies. Panel (a) in Figure 7 shows the average ratio of trade openness (the sum of exports and imports as a ratio to GDP) to the investment rate (as a ratio to GDP) from 1990 to 2006 for different groups of developing countries. While the ratio for the group of non-emerging market Asian developing economies is below the average for the entire group of developing countries, the ratio for the Asian emerging market economies (EMG) is the highest among the regional subgroups. This means that the results shown in columns (4) through (6) of Tables 5-1 and 5-2 are more relevant to this group of economies than any other group. Our estimation results indicate that more open economies could reduce volatility in both investment and real exchange rate by pursuing more stable exchange rate as long as they hold higher levels of IR. Panels (b) through (d) show the period averages of IR holding (\% of GDP), ERS, and MI, respectively. In Panel (b), the level of IR holding for the Asian EMG is much greater than the threshold of $15-16 \%$ we just discussed above, though both ERS and MI are around the group averages of developing countries. These panels of figures at least indicate that Asian emerging market economies seem to have pursued international macroeconomic policies that allow their massive IR holding to reduce the level of volatility in both investment and the real exchange rates. In fact, according to Figure 8, the level of investment volatility for Asian EMGs is lower than any other group of developing countries and comparable to that of industrialized countries (except for the 1990s because of the Asian crisis). These economies have also achieved low levels of real exchange rate volatility, again comparable to that of industrialized countries. 
Figure 7: Regional Comparison of Trade Openness and Exchange Rate Stability

(a) Ratio of Trade Openness ((EX+IM)/Y)

to Investment Rate (\% of GDP): 1990-2006

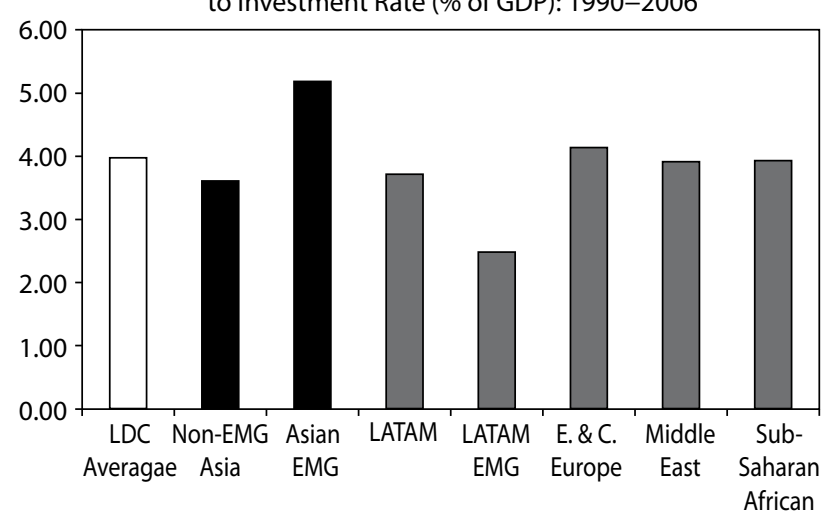

(b) International Reserves as Percent of GDP 1990-2008

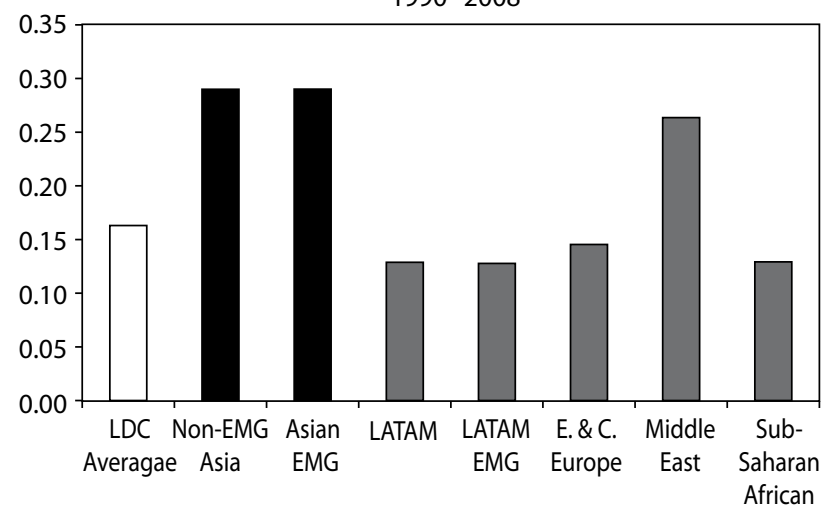

(c) Exchange Rate Stability (ERS) 1990-2008

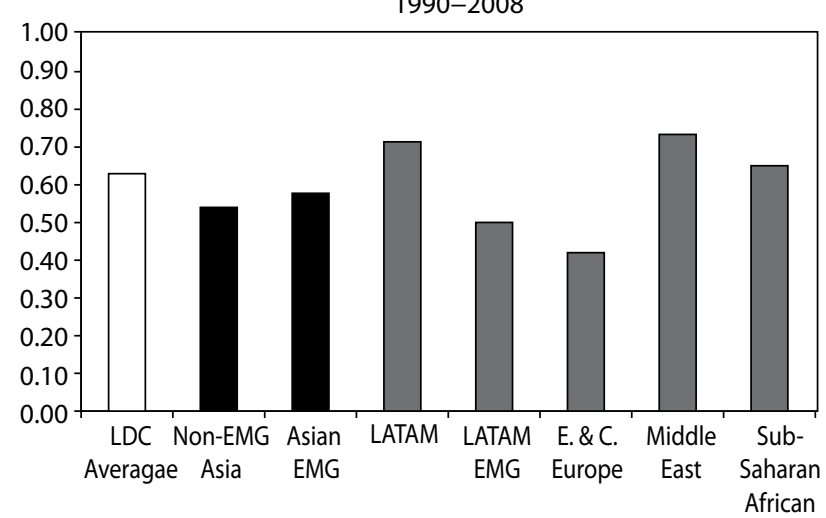

(d) Monetary Independence (MI)

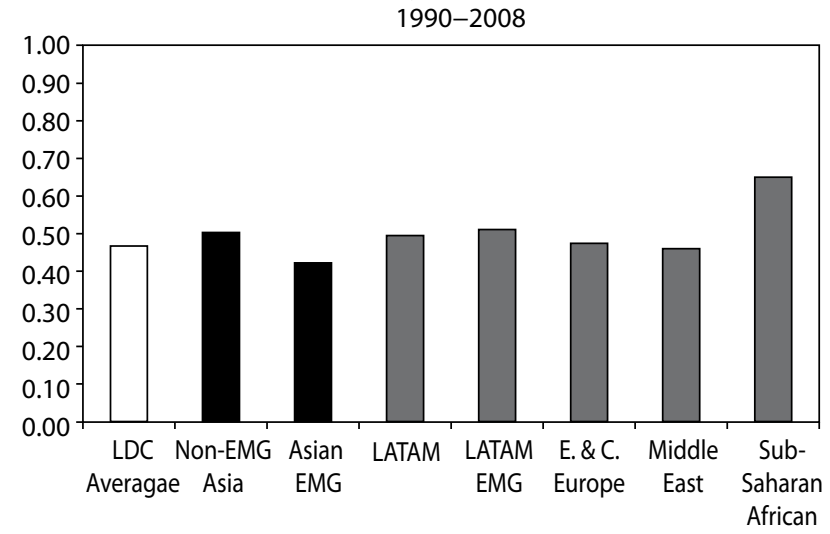

$E \& C=$ east and central, EMG = emerging market economies, GDP = gross domestic product, LATAM = Latin America, LDC $=$ less developed countries. 
Table 5-2: Determinants of Output Volatility: Emerging Market Economies (EMG)

\begin{tabular}{|c|c|c|c|c|c|c|}
\hline & \multicolumn{3}{|c|}{ Investment volatility } & \multicolumn{3}{|c|}{ Real exchange rate volatility } \\
\hline & (1) & $(2)$ & (3) & (4) & (5) & (6) \\
\hline Relative Income & $\begin{array}{c}0.237 \\
{[0.254]}\end{array}$ & $\begin{array}{c}0.119 \\
{[0.272]}\end{array}$ & $\begin{array}{c}0.193 \\
{[0.255]}\end{array}$ & $\begin{array}{c}-0.045 \\
{[0.054]}\end{array}$ & $\begin{array}{c}0.072 \\
{[0.074]}\end{array}$ & $\begin{array}{c}-0.073 \\
{[0.050]}\end{array}$ \\
\hline Relative Income, sq. & $\begin{array}{c}-0.625 \\
{[0.557]}\end{array}$ & $\begin{array}{l}-0.36 \\
{[0.604]}\end{array}$ & $\begin{array}{c}-0.452 \\
{[0.561]}\end{array}$ & $\begin{array}{c}0.099 \\
{[0.118]}\end{array}$ & $\begin{array}{c}-0.108 \\
{[0.166]}\end{array}$ & $\begin{array}{c}0.176 \\
{[0.112]}\end{array}$ \\
\hline $\begin{array}{l}\text { Change in US real interest } \\
\text { rate }\end{array}$ & $\begin{array}{l}-0.1 \\
{[0.218]}\end{array}$ & $\begin{array}{l}-0.07 \\
{[0.232]}\end{array}$ & $\begin{array}{c}-0.134 \\
{[0.212]}\end{array}$ & & & \\
\hline Volatility of $\mathrm{TOT}^{*} \mathrm{OPN}$ & $\begin{array}{c}-0.098 \\
{[0.056]^{*}}\end{array}$ & $\begin{array}{c}-0.022 \\
{[0.059]}\end{array}$ & $\begin{array}{l}-0.09 \\
{[0.055]}\end{array}$ & $\begin{array}{c}0.021 \\
{[0.011]^{*}}\end{array}$ & $\begin{array}{c}0.002 \\
{[0.016]}\end{array}$ & $\begin{array}{c}0.019 \\
{[0.010]^{*}}\end{array}$ \\
\hline $\begin{array}{l}\text { Inflation volatility } \\
\text { (Infl. vol. differentials in } \\
\text { (4)-(6)) }\end{array}$ & $\begin{array}{l}0.143 \\
{[0.028]^{* * *}}\end{array}$ & $\begin{array}{l}0.151 \\
{[0.029]^{* * *}}\end{array}$ & $\begin{array}{l}0.142 \\
{[0.027]^{* * *}}\end{array}$ & $\begin{array}{l}0.05 \\
{[0.006]^{* * *}}\end{array}$ & $\begin{array}{l}0.038 \\
{[0.008]^{* * *}}\end{array}$ & $\begin{array}{l}0.051 \\
{[0.005]^{* * *}}\end{array}$ \\
\hline Fiscal Procyclicality & $\begin{array}{c}0.017 \\
{[0.010]}\end{array}$ & $\begin{array}{c}0.014 \\
{[0.011]}\end{array}$ & $\begin{array}{l}0.02 \\
{[0.010]^{*}}\end{array}$ & & & \\
\hline Trade openness & & & & $\begin{array}{c}-0.004 \\
{[0.005]}\end{array}$ & $\begin{array}{c}-0.004 \\
{[0.006]}\end{array}$ & $\begin{array}{c}-0.006 \\
{[0.004]}\end{array}$ \\
\hline Currency Crisis & $\begin{array}{l}0.038 \\
{[0.012]^{* * *}}\end{array}$ & $\begin{array}{c}0.033 \\
{[0.013]^{* *}}\end{array}$ & $\begin{array}{l}0.034 \\
{[0.012]^{* * *}}\end{array}$ & $\begin{array}{l}0.011 \\
{[0.003]^{* * *}}\end{array}$ & $\begin{array}{c}0.013 \\
{[0.003]^{* * *}}\end{array}$ & $\begin{array}{l}0.009 \\
{[0.002]^{* * *}}\end{array}$ \\
\hline Private credit creation & $\begin{array}{c}0.025 \\
{[0.024]}\end{array}$ & $\begin{array}{c}0.004 \\
{[0.025]}\end{array}$ & $\begin{array}{c}0.033 \\
{[0.024]}\end{array}$ & & & \\
\hline Total Reserve (as \% of GDP) & $\begin{array}{c}-0.374 \\
{[0.192]^{*}}\end{array}$ & $\begin{array}{l}-1.045 \\
{[0.211]^{* * *}}\end{array}$ & $\begin{array}{l}0.368 \\
{[0.118]^{* * *}}\end{array}$ & $\begin{array}{c}0.035 \\
{[0.040]}\end{array}$ & $\begin{array}{c}0.052 \\
{[0.058]}\end{array}$ & $\begin{array}{c}0.001 \\
{[0.023]}\end{array}$ \\
\hline $\begin{array}{l}\text { Monetary Independence } \\
\text { (MI) }\end{array}$ & $\begin{array}{l}-0.286 \\
{[0.060]^{* * *}}\end{array}$ & $\begin{array}{l}-0.365 \\
{[0.066]^{* * *}}\end{array}$ & & $\begin{array}{c}0.027 \\
{[0.013]^{* *}}\end{array}$ & $\begin{array}{c}0.042 \\
{[0.018]^{* *}}\end{array}$ & \\
\hline MI $x$ reserves & $\begin{array}{l}1.867 \\
{[0.306]^{* * *}}\end{array}$ & $\begin{array}{l}2.095 \\
{[0.353]^{* * *}}\end{array}$ & & $\begin{array}{l}-0.068 \\
{[0.064]}\end{array}$ & $\begin{array}{c}-0.123 \\
{[0.096]}\end{array}$ & \\
\hline $\begin{array}{l}\text { Exchange Rate Stability } \\
\text { (ERS) }\end{array}$ & $\begin{array}{l}0.127 \\
{[0.032]^{* * *}}\end{array}$ & & $\begin{array}{l}0.121 \\
{[0.030]^{* * *}}\end{array}$ & $\begin{array}{l}-0.039 \\
{[0.007]^{* * *}}\end{array}$ & & $\begin{array}{l}-0.037 \\
{[0.006]^{* * *}}\end{array}$ \\
\hline ERS $x$ reserves & $\begin{array}{l}-0.818 \\
{[0.183]^{* * *}}\end{array}$ & & $\begin{array}{l}-0.583 \\
{[0.173]^{* * *}}\end{array}$ & $\begin{array}{c}-0.012 \\
{[0.037]}\end{array}$ & & $\begin{array}{c}-0.006 \\
{[0.033]}\end{array}$ \\
\hline KA Openness & & $\begin{array}{l}-0.065 \\
{[0.034]^{*}}\end{array}$ & $\begin{array}{c}0.026 \\
{[0.029]}\end{array}$ & & $\begin{array}{c}-0.001 \\
{[0.009]}\end{array}$ & $\begin{array}{c}-0.009 \\
{[0.006]}\end{array}$ \\
\hline KAOPEN $x$ reserves & & $\begin{array}{l}0.414 \\
{[0.175]^{* *}}\end{array}$ & $\begin{array}{c}-0.138 \\
{[0.144]}\end{array}$ & & $\begin{array}{l}-0.013 \\
{[0.047]}\end{array}$ & $\begin{array}{c}0.011 \\
{[0.028]}\end{array}$ \\
\hline Net FDI inflows/GDP & $\begin{array}{c}-0.216 \\
{[0.373]}\end{array}$ & $\begin{array}{c}0.237 \\
{[0.422]}\end{array}$ & $\begin{array}{c}-0.433 \\
{[0.384]}\end{array}$ & $\begin{array}{c}-0.054 \\
{[0.081]}\end{array}$ & $\begin{array}{c}-0.114 \\
{[0.117]}\end{array}$ & $\begin{array}{c}0.024 \\
{[0.077]}\end{array}$ \\
\hline Net portfolio inflows/GDP & $\begin{array}{c}0.76 \\
{[0.488]}\end{array}$ & $\begin{array}{c}1.34 \\
{[0.543]^{* *}}\end{array}$ & $\begin{array}{c}0.736 \\
{[0.497]}\end{array}$ & $\begin{array}{c}-0.043 \\
{[0.102]}\end{array}$ & $\begin{array}{c}-0.149 \\
{[0.147]}\end{array}$ & $\begin{array}{c}-0.018 \\
{[0.097]}\end{array}$ \\
\hline Net 'other' inflows/GDP & $\begin{array}{l}0.586 \\
{[0.131]^{* * *}}\end{array}$ & $\begin{array}{l}0.637 \\
{[0.139]^{* * *}}\end{array}$ & $\begin{array}{l}0.6 \\
{[0.127]^{* * *}}\end{array}$ & $\begin{array}{l}-0.078 \\
{[0.027]^{* * *}}\end{array}$ & $\begin{array}{l}-0.08 \\
{[0.038]^{* *}}\end{array}$ & $\begin{array}{l}-0.056 \\
{[0.025]^{* *}}\end{array}$ \\
\hline $\begin{array}{l}\text { Short-term Debt } \\
\text { (as \% of total external } \\
\text { debt) }\end{array}$ & $\begin{array}{l}-0.102 \\
{[0.067]}\end{array}$ & $\begin{array}{l}-0.07 \\
{[0.072]}\end{array}$ & -0.113 & $\begin{array}{l}0.014 \\
{[0.013]}\end{array}$ & $\begin{array}{l}-0.002 \\
{[0.017]}\end{array}$ & $\begin{array}{l}0.009 \\
{[0.011]}\end{array}$ \\
\hline $\begin{array}{l}\text { Total debt service } \\
\text { (as \% of GNI) }\end{array}$ & $\begin{array}{c}0.172 \\
{[0.155]}\end{array}$ & $\begin{array}{c}0.277 \\
{[0.165]^{*}}\end{array}$ & $\begin{array}{c}0.182 \\
{[0.151]}\end{array}$ & $\begin{array}{c}0.027 \\
{[0.038]}\end{array}$ & $\begin{array}{c}0.034 \\
{[0.052]}\end{array}$ & $\begin{array}{c}0.032 \\
{[0.035]}\end{array}$ \\
\hline Observations & 149 & 149 & 149 & 151 & 151 & 151 \\
\hline Adjusted R-squared & 0.62 & 0.49 & 0.49 & 0.68 & 0.39 & 0.69 \\
\hline
\end{tabular}

$\mathrm{FDI}=$ foreign direct investment, $\mathrm{GDP}=$ gross domestic product, $\mathrm{GNI}=$ gross national income, $\mathrm{KA}=$ capital account, KAOPEN = capital account openness, TOT $=$ terms of trade, US $=$ United States.

Robust regressions are implemented. * significant at 10\%; ${ }^{* *}$ significant at $5 \%$; ${ }^{* *}$ significant at $1 \%$. The dummy for Sub-Saharan countries is included in the regressions for output and inflation volatility, so are the dummies for Latin America and Caribbean and East Europe and Central Asia in the regression for the level of inflation.

Source: Authors' calculations. 
Figure 8: Regional Comparison of Investment Volatility and Real Exchange Rate Volatility
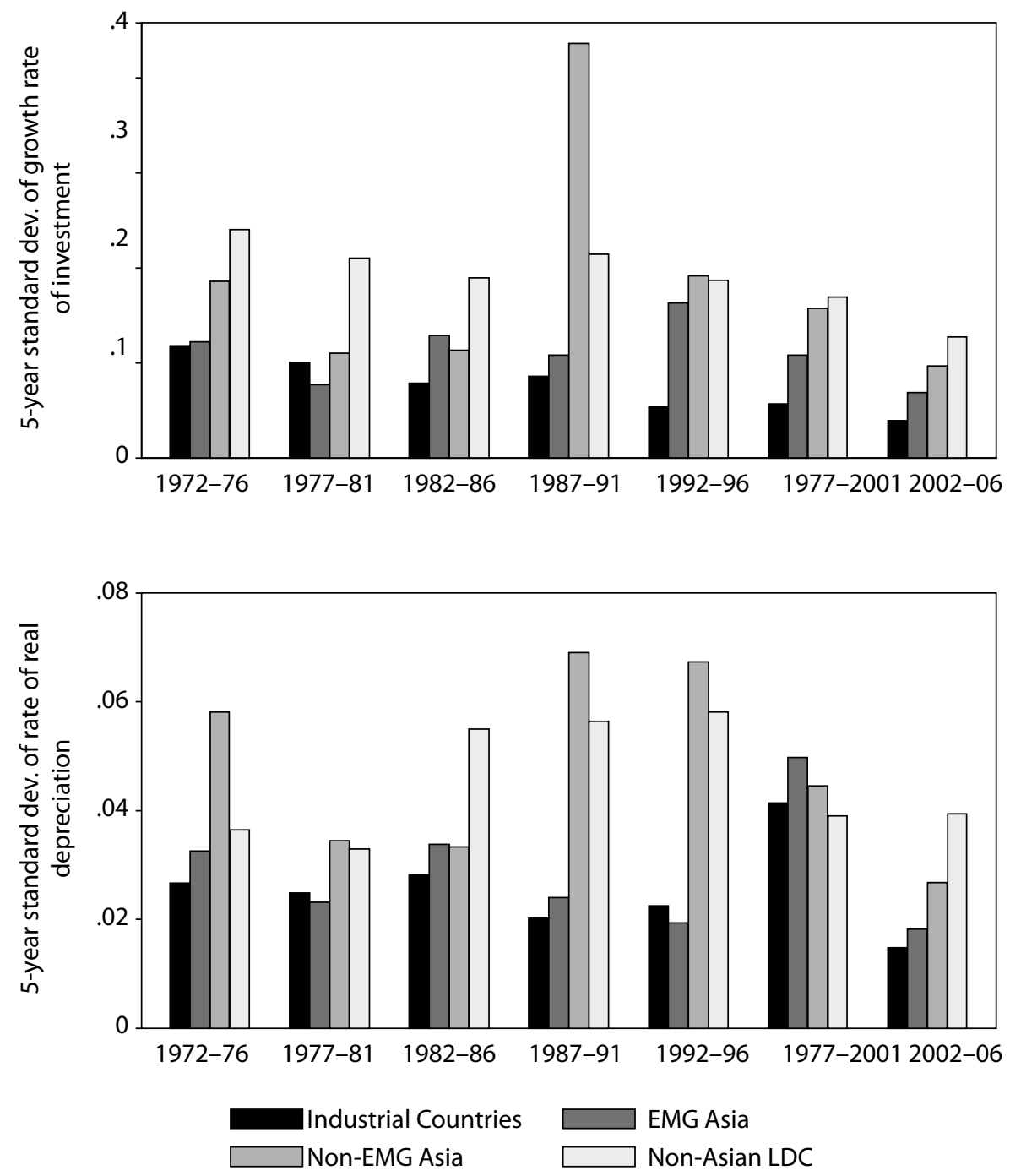

$E M G$ = emerging market economies, $L D C=$ less developing country.

Figure 9 illustrates the estimated effects of the three trilemma variables on investment volatility and real exchange rate volatility calculated using the estimation results shown in Table 5-1.39 The panels of Figure 9 allow us to make four interesting observations for the Asian economies. First, exchange rate stability and its interaction with IR holding have contributed significantly to lowering the real exchange rate volatility over years, which is also the case with the non-Asian developing economies (bottom two panels). Second,

39 That is, the bars in the panels of figures refer to $\breve{\alpha}_{1} T L M_{i t}+\breve{\alpha}_{3}\left(T L M_{i t} \times I R_{i t}\right)$ for each of the trilemma indexes and its interaction with IR holding. The estimated effects are calculated using the estimated coefficients and actual values for the trilemma indexes and the IR ratio. However, because only two out of the three trilemma variables are included in the estimations, the estimation results from two types of regressions: one with $M I$ and $E R S$ included in $T L M_{i t}$ and the other with ERS and KAOPEN, are used to calculate the estimated effects for all the three indexes. The estimated effect of ERS is, however, based on the average of the estimated coefficients for the two regressions. 
among Asian developing economies, exchange rate stability and its interaction with IR holding lowered investment volatility especially in 2002-2006. Third, the three policies, on net, appear to have contributed negatively to volatilities in both investment and real exchange rate in the post-Asian crisis period. Last, the effect of financial openness and $\mathrm{IR}$ holding is minimal for this group of economies.

\section{Figure 9: The Impacts of the Trilemma Configurations on Investment Volatility and Real} Exchange Rate Volatility
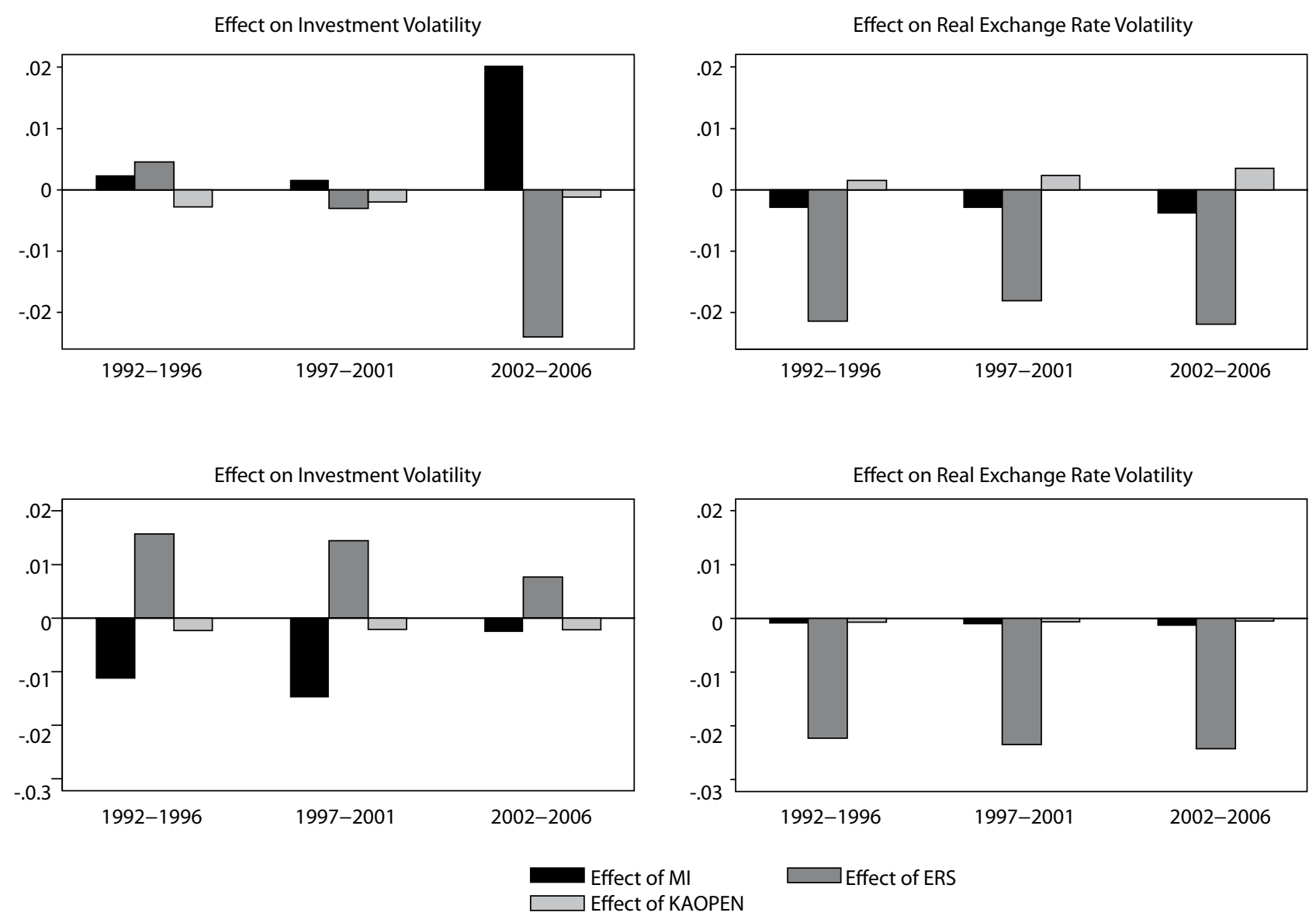

ERS $=$ exchange rate stability, $\mathrm{KAOPEN}=$ capital account openness, $\mathrm{MI}=$ monetary independence.

For the non-Asian developing economies, on the other hand, it is monetary independence that has been a negative contributor to investment volatility over years though its impact dwindled in the last period. Furthermore, unlike the Asian subgroup, exchange rate stability has been a positive contributor to investment volatility though its impact seems to have been trending downward. Hence, the Asian economies seem to have been able to lessen the volatilities of investment and real exchange rate by pursuing greater ERS and having high levels of IR especially in the last 5-year period. 


\section{Concluding Remarks}

About 1 year after the onset of the most severe global crisis since the Great Depression, in the summer of 2009, we started observing some signs of recovery, though none of them yet suggested sustainable recovery. Among the economies with signs of recovery, Asia has impressed the world with its most robust recovery, attracting scrutiny from both the academic and policy communities. ${ }^{40}$ This paper attempted to make an addition to the scrutiny by focusing on how the region has dealt with the waves of financial globalization through configuring international macroeconomic policies. For this exploration, we have focused on a fundamental principle in international finance, called the "impossible trinity" or "trilemma"-an economy can concurrently implement at full capacity only two out of the three international macroeconomic policies: monetary independence, exchange rate stability, and financial openness.

The "trilemma indexes" developed by Aizenman et al. (2008) allow us to trace the changing patterns of the trilemma configurations among countries and bring to light striking differences between the choices of industrialized and developing countries during 1970-2007. The recent trend suggests that industrialized countries have been experiencing divergence of the three dimensions of the trilemma, and moved toward the configuration of high exchange rate stability and financial openness and low monetary independence as most distinctively exemplified by the euro countries' experience. Emerging market economies, on the other hand, appear to be converging toward a "middle ground" with managed exchange rate flexibility, while maintaining medium levels of monetary independence and financial integration. Interestingly, for Asian emerging market economies, convergence is not a recent phenomenon; since as early as the 1980s, the three indexes have been clustered around the middle range, though exchange rate stability has been the most pervasive policy choice. Another, more recent iconic trait of this group of economies is the high level of IR holding, which this paper also incorporates into the analysis.

The fact that policy configurations based on the trilemma have evolved over the years must mean that combinations of the three policies should have strengths and weaknesses in terms of managing the macroeconomy. As such, this study examined how trilemma policy configurations can affect various aspects of macroeconomic performances, namely, per capita output growth, output volatility, inflation volatility, and the medium-term rate of inflation in an attempt to explain why the economies in the Asian region, especially those with emerging markets, have achieved stable macroeconomic development. To reveal potential uniqueness of the Asian economies, we resorted to panel data analysis to examine the correlation between trilemma configurations and macroeconomic performances while properly controlling for the complexity of other macroeconomic conditions.

40 See the 15 August 2009 issue of The Economist for a report on Asia's recovery from the financial crisis of 20082009. 
A series of empirical analyses yielded interesting findings. First, the results from the growth regressions provided very weak evidence that per capita economic growth can be affected by policy choices among the three trilemma policies as well as external finances such as cross-border flows of FDI, portfolio investment, and bank lending. This finding is not surprising given that theory predicts conflicting effects on economic growth for all the three policy goals. Our estimation results confirmed the ambivalence.

Second, we investigated how the policy configurations based on the trilemma affect other macroeconomic performances such as output volatility, inflation volatility, and the medium-term level of inflation, and found some of the policy choices significantly affect output volatility and the rate of inflation. More specifically, higher levels of monetary independence are associated with lower output volatility. Countries with higher levels of exchange rate fixity tend to experience higher output volatility, though this effect can be mitigated by holding a higher level of international reserves than the threshold of about $20 \%$ of GDP. This result is consistent with the phenomenon of many emerging market economies accumulating massive international reserves.

We also found that countries with greater monetary autonomy tend to experience higher inflation while countries with higher exchange rate stability tend to experience lower inflation. Furthermore, financial openness helps a country to achieve lower inflation. However, we found some evidence that if countries pursue greater exchange rate stability and financial openness while holding a sizeable amount of international reserves through foreign exchange intervention, they can experience a rise in the level of inflation, suggesting that countries with excess levels of reserves holding may eventually face a limit in foreign exchange sterilization.

We focused on the impact of the trilemma policy configurations on output volatility and examined through what channels the trilemma policy configurations affect output volatility. The estimation results of the regression on investment volatility turned out to share similar characteristics with the regression on output volatility, suggesting that trilemma policy configurations and external finances affect output volatility through investment. More specifically, like in the estimation on output volatility, greater monetary independence is found to help reduce investment volatility. However, if the level of IR holding gets above 15-20\% of GDP, greater monetary independence would become volatility-enhancing for investment by providing too much liquidity and thereby making the cost of capital too volatile. While a higher degree of exchange rate stability could stabilize the real exchange rate movement, it could also make investment volatile, though the volatility-enhancing effect of exchange rate stability on investment can be cancelled by holding higher levels of IR. Greater financial openness is found to help reduce real exchange rate volatility. These results indicate that policy makers in a more open economy would prefer pursuing greater exchange rate stability and greater financial openness while holding a massive amount of IR because this policy combination would help them stabilize both investment and real exchange rate. This finding might help explain why small, open economies in East Asia hold massive amounts of IR. 
Overall, Asian economies, especially the ones with emerging markets, are found to be equipped with macroeconomic policy configurations that help the economies to dampen the volatilities in both investment and real exchange rate. These economies' sizeable amount of IR holding appears to help enhance the stabilizing effect of the trilemma policy choices, which explains the recent phenomenal buildup of IR in the region. 


\title{
Appendix 1: Construction of the Trilemma Measures
}

\author{
Monetary Independence (MI)
}

The extent of monetary independence is measured as the reciprocal of the annual correlation of the monthly interest rates between the home country and the base country. Money market rates are used. ${ }^{1}$

The index for the extent of monetary independence is defined as:

$M I=1-\frac{\operatorname{corr}\left(i_{i}, i_{j}\right)-(-1)}{1-(-1)}$

where $i$ refers to home countries and $j$ to the base country. By construction, the maximum value is 1 , and the minimum value is 0 . Higher values of the index mean more monetary policy independence. ${ }^{2,3}$

Here, the base country is defined as the country that a home country's monetary policy is most closely linked with as in Shambaugh (2004). The base countries are Australia, Belgium, France, Germany, India, Malaysia, South Africa, the United Kingdom, and the United States. For the countries and years for which Shambaugh's data are available, the base countries from his work are used, and for the others, the base countries are assigned based on the International Monetary Fund's Annual Report on Exchange Arrangements and Exchange Restrictions and Central Intelligence Agency Factbook.

\section{Exchange Rate Stability (ERS)}

To measure exchange rate stability, annual standard deviations of the monthly exchange rate between the home country and the base country are calculated and included in the following formula to normalize the index between 0 and 1 :

1 The data are extracted from the IMF's International Financial Statistics (60B..ZF...). For the countries whose money market rates are unavailable or extremely limited, the money market data are supplemented by those from the Bloomberg terminal and also by the discount rates $(60 . . . Z F . .$.$) and the deposit rates (60L..ZF...) series from IFS.$

2 The index is smoothed out by applying the 3-year moving averages encompassing the preceding, concurrent, and following years $(t-1, t, t+1)$ of observations.

3 We note one important caveat about this index. Among some countries and in some years, especially early ones, the interest rate used for the calculation of the $\mathrm{MI}$ index is often constant throughout a year, making the annual correlation of the interest rates between the home and base countries $\left(\operatorname{corr}\left(i_{i}, i_{j}\right)\right.$ in the formula) undefined. Since we treat the undefined corr the same as zero, it makes the MI index value 0.5 . One may think that the policy interest rate being constant (regardless of the base country's interest rate) is a sign of monetary independence. However, it can reflect the possibilities not only that (i) the home country's monetary policy is independent from the base country's; but also (ii) the home country uses other tools to implement monetary policy than manipulating the interest rates, such as changing the required reserve ratios and providing some window guidance (while leaving the policy interest rate unchanged); and/or that (iii) the home country implements a strong control on financial intermediary, including credit rationing, that makes the policy interest rate appear constant. To make the matter more complicated, some countries have used (ii) and (iii) to exercise monetary independence while others have used them while strictly following the base country's monetary policy. The bottom line is that it is impossible to incorporate these issues in the calculation of MI without over- or underestimating the degree of monetary independence. Therefore, assigning an MI value of 0.5 for such a case should be a reasonable compromise. However, it does not preclude the necessity of robustness checks on the index, which we plan to undertake. 
$E R S=\frac{0.01}{0.01+\operatorname{stdev}(\Delta(\log (\text { exch_rate }))}$

Merely applying this formula can easily create a downward bias in the index, that is, it would exaggerate the "flexibility" of the exchange rate especially when the rate usually follows a narrow band, but is de- or revalued infrequently. ${ }^{4}$ To avoid such downward bias, we also apply a threshold to the exchange rate movement as has been done in the literature. That is, if the rate of monthly change in the exchange rate stayed within $+/-0.33$ percent bands, we consider the exchange rate is "fixed" and assign the value of one for the ERS index. Furthermore, single year pegs are dropped because they are quite possibly not intentional ones. ${ }^{5}$ Higher values of this index indicate more stable movement of the exchange rate against the currency of the base country.

\section{Financial Openness/Integration (KAOPEN)}

Without question, it is extremely difficult to measure the extent of capital account controls. ${ }^{6}$ Although many measures exist to describe the extent and intensity of capital account controls, it is generally agreed that such measures fail to capture fully the complexity of real-world capital controls. Nonetheless, for the measure of financial openness, we use the index of capital account openness, or KAOPEN, by Chinn and Ito $(2006,2008)$. KAOPEN is based on information regarding restrictions in the International Monetary Fund's Annual Report on Exchange Arrangements and Exchange Restrictions. Specifically, KAOPEN is the first standardized principal component of the variables that indicate the presence of multiple exchange rates, restrictions on current account transactions, on capital account transactions, and the requirement of the surrender of export proceeds. ${ }^{7}$ Since KAOPEN is based on reported restrictions, it is necessarily a de jure index of capital account openness (in contrast to de facto measures such as those in Lane and Milesi-Ferretti [2006]). The choice of a de jure measure of capital account openness is driven by the motivation to look into policy intentions of the countries; de facto measures are more susceptible to other macroeconomic effects than solely policy decisions with respect to capital controls. ${ }^{8}$

The Chinn-Ito index is normalized between zero and one. Higher values of this index indicate that a country is more open to cross-border capital transactions. The index is originally available for 181 countries for 1970 through $2006 . .^{9}$ The data set we examine does not include the United States.

4 In such a case, the average of the monthly change in the exchange rate would be so small that even small changes could make the standard deviation big and thereby the ERS value small.

5 The choice of the $+/-0.33$ percent bands is based on the $+/-2 \%$ band based on the annual rate, that is often used in the literature. Also, to prevent breaks in the peg status due to one-time realignments, any exchange rate that had a percentage change of 0 in 11 out of 12 months is considered fixed. When there are two re/devaluations in 3 months, then they are considered to be one re/devaluation event, and if the remaining 10 months experience no exchange rate movement, then that year is considered to be the year of fixed exchange rate. This way of defining the threshold for the exchange rate is in line with the one adopted by Shambaugh (2004).

6 See Chinn and Ito (2008), Edison and Warnock (2001), Edwards (2001), Edison et al. (2002), and Kose et al. (2006) for discussions and comparisons of various measures on capital restrictions.

7 This index is described in greater detail in Chinn and Ito (2008).

8 De jure measures of financial openness also face their own limitations. As Edwards (1999) discusses, it is often the case that the private sector circumvents capital account restrictions, nullifying the expected effect of regulatory capital controls. Also, International Monetary Fund-based variables are too aggregated to capture the subtleties of actual capital controls, that is, the direction of capital flows (i.e., inflows or outflows) as well as the type of financial transactions targeted.

9 The original dataset covers 181 countries, but data availability is uneven among the three indexes. MI is available for 172 countries; ERS for 182; and KAOPEN for 178. Both MI and ERS start in 1960 whereas KAOPEN in 1970. For $\mathrm{MI}$ and ERS are updated to 2008 while KAOPEN is updated only to 2007 because the information ion AREAER is available up to 2007. 


\section{Appendix 2: List of "Asian Economies" in the Sample}

\begin{tabular}{|c|c|}
\hline & $\begin{array}{l}\text { Emerging Market } \\
\text { Economies }\end{array}$ \\
\hline Armenia* & 0 \\
\hline Azerbaijan* & 0 \\
\hline Bangladesh & 0 \\
\hline Bhutan* & 0 \\
\hline Cambodia & 1 \\
\hline People's Republic of China & 1 \\
\hline Fiji Islands & 0 \\
\hline Georgia & 0 \\
\hline Hong Kong, China & 1 \\
\hline India & 1 \\
\hline Indonesia & 1 \\
\hline Kazakhstan* & 0 \\
\hline Kyrgyz Republic** & 0 \\
\hline Korea, Republic of & 1 \\
\hline Lao People's Democratic Republic & 0 \\
\hline Malaysia & 1 \\
\hline Maldives* & 0 \\
\hline Micronesia, Federated States of* & 0 \\
\hline Mongolia & 0 \\
\hline Myanmar* & 0 \\
\hline Nepal & 0 \\
\hline Pakistan & 0 \\
\hline Papua New Guinea* & 0 \\
\hline Philippines & 1 \\
\hline Samoa* & 0 \\
\hline Singapore & 1 \\
\hline Solomon Islands & 0 \\
\hline Sri Lanka & 0 \\
\hline Tajikistan* & 0 \\
\hline Thailand & 1 \\
\hline Tonga* & 0 \\
\hline Turkmenistan* & 0 \\
\hline Uzbekistan & 0 \\
\hline Viet Nam & 1 \\
\hline
\end{tabular}

Note: * - not included in the regression estimations 


\section{References}

Aghion, P., A. Banerjee, and T. Piketty. 1999. "Dualism and Macroeconomic Volatility." Quarterly Journal of Economics 114:1359-1397.

Aghion, Philippe, Philippe Bacchetta, Romain Ranciere, and Kenneth S. Rogoff. 2005. "Productivity Growth and the Exchange Rate Regime: The Role of Financial Development." Universitat Pompeu Fabra (UPF) Economics and Business Working Paper No. 850. Barcelona, Spain: UPF.

Aizenman, J., M.D. Chinn, and H. Ito. 2009. "The Financial Crisis, Rethinking of the Global Financial Architecture, and the Trilemma." Mimeo. Portland State University.

Aizenman, J., M.D. Chinn, and H. Ito. 2008. "Assessing the Emerging Global Financial Architecture: Measuring the Trilemma's Configurations Over Time." National Bureau of Economic Research (NBER) Working Paper Series \#14533. Cambridge, Massachusetts: National Bureau of Economic Research. (December 2008; revised in April 2009).

Aizenman, J. and R. Glick. 2008. "Sterilization, Monetary Policy, and Global Financial Integration." Mimeo. University of California, Santa Cruz. Forthcoming in Review of International Economics.

Aizenman, J. and Y. Jinjarak. 2008. "The US as the "Demander of Last Resort" and its Implications on China's Current Account." NBER Working Paper \#14453. Cambridge, Massachusetts: National Bureau of Economic Research. (October).

Alesina, A. and Summers, L., 1993. "Central Bank Independence and Macroeconomic Performance." Journal of Money, Credit and Banking 25:151-162

Barro, R. and Gordon, D. 1983. "A Positive Theory of Monetary Policy in a Natural Rate Model." Journal of Political Economy 91:589-610.

Barro, R. J., and J.W. Lee. 2001. "International Data on Educational Attainment: Updates and Implications." Oxford Economic Papers 53(3):541-563.

Blankenau,W.,M.A. Kose, and K. Yi. 2001. "Can World Real Interest Rates Explain Business Cycles in a Small Open Economy?" Journal of Economic Dynamics and Control 25:867-889.

Caballero, R.J., and A. Krishnamurthy. 2001. "International and Domestic Collateral Constraints in a Model of Emerging Market Crises." Journal of Monetary Economics 48:513-548.

Calvo, G.A., A. Izquierdo and L.F. Mejía. 2004. "On the Empirics of Sudden Stops: The Relevance of Balance-Sheet Effects." Research Department Working Paper 509. Washington, D.C., United States: Inter-American Development Bank.

Cavallo, E.A. 2007. "Output Volatility and Openness to Trade: A Reassessment." Inter-American Development Bank Working Paper \#604. Washington, D.C.: Inter-American Development Bank. (April).

Cavallo, E.A. 2005. "Trade, Gravity and Sudden Stops: On How Commercial Trade Openness Can Increase the Stability of Capital Flows." Mimeo. Cambridge, United States: Harvard University.

Cavallo, E.A., and J.A. Frankel. 2004. "Does Openness to Trade Make Countries More Vulnerable to Sudden Stops, or Less?" NBER Working Paper 10957. Cambridge, Massachusetts: National Bureau of Economic Research.

Cecchetti, S.G. and M. Ehrmann. 1999. "Does Inflation Targeting Increase Output Volatility? An International Comparison Of Policymakers' Preferences And Outcomes." NBER Working Paper \#7426. Cambridge, Massachusetts: National Bureau of Economic Research.

Chinn, M. D. and H. Ito. 2008. "A New Measure of Financial Openness." Journal of Comparative Policy Analysis 10(3):309-322.

Chinn, M. D. and H. Ito. 2006. "What Matters for Financial Development? Capital Controls, Institutions, and Interactions." Journal of Development Economics 81(1):163-192 (October). 
De Grauwe, P. and G. Schnabl. 2004. "Exchange Rates Regimes and Macroeconomic Stability in Central and Eastern Europe." CESifo Working Paper 1182:1-34.

Dubas, J. M., B. J. Lee, and N. C. Mark. 2005. "Effective Exchange Rate Classifications and Growth." NBER Working Paper No. W11272. Cambridge, Massachussetts: NBER.(April).

Easterly, W., R. Islam and J. Stiglitz. 2001. "Shaken and Stirred: Explaining Growth Volatility." In B. Plesokovic and N. Stern, eds. Annual World Bank Conference on Development Economics. Washington, DC, United States: World Bank.

Edison, Hali J., M. W. Klein, L. Ricci, and T. Sløk. 2002. "Capital Account Liberalization and Economic Performance: A Review of the Literature." IMF Working Paper. Washington, D.C.: International Monetary Fund. (May).

Edison, Hali J. and F. E. Warnock. 2001. "A simple measure of the intensity of capital controls," International Finance Discussion Paper \#708 Washington, D.C.: Board of Governors of the Federal Reserve System. (September).

Edwards, S. 2001. "Capital Mobility and Economic Performance: Are Emerging Economies Different?" NBER Working Paper No. 8076. Cambridge, Massachusetts: National Bureau of Economic Research.

Edwards, S., 1999. "How effective are capital controls?" Journal of Economic Perspectives 13: 65-84.

Edwards, S. and E. Levy-Yeyati. 2005. "Flexible exchange rates as shock absorbers." European Economic Review 49(8): 2079-2105. (November).

Eichengreen, B. and D. Leblang. 2003. Exchange Rates and Cohesion: Historical Perspectives and Political-Economy Considerations. Journal of Common Market Studies 41(5): 797-822.

Eichengreen, B., Rose, A. K., and Wyplosz, C. 1996. "Contagious Currency Crises." NBER Working Paper 5681. Cambridge, Massachusetts: National Bureau of Economic Research.

Glick, R. and M. Hutchison. 2008. "Are Capital Controls Effective? Duration of Capital Controls and the Survival of Pegged Exchange Rate Regimes with Special Reference to the People's Republic of China." Mimeo. University of California, Santa Cruz.

Glick, R. and M. Hutchison. 2001. "Banking and Currency Crises: How Common Are Twins?" In R. Glick, R. Moreno, and M. Spiegel, eds. Financial Crises in Emerging Markets. Cambridge, UK: Cambridge University Press.

Ghosh, A., A. Gulde and J. Ostry. 1997. "Does the Nominal Exchange Rate Regime Matter?" NBER Working Paper No 5874. Cambridge, Massachusetts: National Bureau of Economic Research.

Haruka, D. S. 2007. "Output Volatility and Large Output Drops in Emerging Market and Developing Countries." IMF Working Paper WP/07/114 (May). Washington, D.C.: International Monetary Fund.

Henry, P. B. 2006. "Capital Account Liberalization: Theory, Evidence, and Speculation." NBER Working Paper No. 12698. Cambridge, Massachusetts: National Bureau of Economic Research

Hnatkovska, V. and N. Loayza. 2005. "Volatility and Growth." In J. Aizenman and B. Pinto, eds. Managing Economic Volatility and Crises: A Practitioner's Guide. Cambridge: Cambridge University Press (October).

Kaminsky, G. and C. Reinhart. 1999. "The Twin Crises: The Causes of Banking and Currency Balance-of-Payments Problems." American Economic Review 89: 473-500.

Kaminsky, G. and S. L. Schmukler. 2002. "Short-Run Pain, Long-Run Gain: The Effects of Financial Liberalization. World Bank Working Paper No. 2912; IMF Working Paper No. 0334. Washington, D.C.: International Monetary Fund. (October).

Kawai, M. and S. Takagi. 2008. "A Survey of the Literature on Managing Capital Inflows." $A D B I$ Discussion Paper \#100. Tokyo: Asian Development Bank Institute. 
Kose, M. A., E. Prasad, K. Rogoff, and S. J. Wei, 2006, "Financial Globalization: A Reappraisal." IMF Working Paper, WP/06/189. Washington, D.C.: International Monetary Fund.

Kose, M.A., E. Prasad and A. D. Taylor. 2009. "Thresholds in the Process of International Financial Integration." NBER Working Paper \#14916. Cambridge, Massachusetts: National Bureau of Economic Research. (April).

Kose, M.A., E. Prasad and M. Terrones. 2003. "Financial Integration and Macroeconomic Volatility." IMF Working Paper WP/03/50. Washington, DC, United States: International Monetary Fund.

Krugman, P., 1993. "Lessons of Massachusetts for EMU." In F. Giavazzi and F. Torres, eds. The Transition to Economic and Monetary Union in Europe. Cambridge: Cambridge University Press. (pp. 241-261).

Lane, P. R. and G.M. Milesi-Ferretti. 2006. "The External Wealth of Nations Mark II: Revised and Extended Estimates of Foreign Assets and Liabilities, 1970-2004." IMF Working Paper 06/69. Washington, D.C.: International Monetary Fund.

Levy-Yeyati, E. and F. Sturzenegger. 2003. "To float or to fix: Evidence on the impact of exchange rate regimes on growth." The American Economic Review 93(4): 1173-1193.

Loungani, P., A. Razin, C. W. Yuen. 2001. "Capital Mobility and the Output-Inflation Tradeoff." Journal of Development Economics 64: 255-274.

Mishkin, F. S. and K. Schmidt-Hebbel. 2007. “Does Inflation Targeting Make a Difference?" NBER Working Paper \#12876. Cambridge, Massachusetts: National Bureau of Economic Research. (January).

Moreno R. and M. M. Spiegel. 1997. "Are Asian economies exempt from the „impossible trinity?": Evidence from Singapore." Federal Reserve Bank of San Francisco, Pacific Basin Working Paper Series. (pp. 97-101).

Obstfeld, M., J.C. Shambaugh, and A.M. Taylor. 2009. "Financial Instability, Reserves, and Central Bank Swap Lines in the Panic of 2008." NBER Working Papers 14826. Cambridge, Massachusetts: National Bureau of Economic Research. (March).

Obstfeld, M., J. C. Shambaugh, and A. M. Taylor. 2008. "Financial Stability, The Trilemma, and International Reserves." NBER Working Paper 14217. Cambridge, Massachusetts: National Bureau of Economic Research. (August).

Obstfeld, M., J. C. Shambaugh, and A. M. Taylor. 2005. "The Trilemma in History: Tradeoffs among Exchange Rates, Monetary Policies, and Capital Mobility." Review of Economics and Statistics 87 (August): 423-438.

Park, Y. C. and J. W. Lee. 2002. "Financial Crisis and Recovery: Patterns of Adjustment in East Asia, 1996-99." Asian Development Bank Institute Research Paper 45. Tokyo: Asian Development Bank Institute. (October).

Prasad, E. S. 2008. "Monetary Policy Independence, the Currency Regime, and the Capital Account in China. In Goldstein, M. and N. R. Lardy, eds. Debating China's Exchange Rate Policy. Washington, D.C.: Peterson Institute for International Economics.

Prasad, E. S. and R. Rajan. 2008. "A Pragmatic Approach to Capital Account Liberalization." NBER Working Paper \#14051. Cambridge, Massachusetts: National Bureau of Economic Research. (June).

Prasad, E.S., K. Rogoff, S. J. Wei, and M. A. Kose. 2003. "Effects of Financial Globalization on Developing Countries: Some Empirical Evidence." Occasional Paper 220. Washington, D.C.: International Monetary Fund.

Prasad, E.S., and S. J. Wei. 2007. "China's Approach to Capital Inflows: Patterns and Possible Explanations. In S. Edwards ed., Capital Controls and Capital Flows in Emerging Economies: Policies, Practices, and Consequences. Chicago: University of Chicago Press.

Razin, A. and A. Binyamini. 2007. "Flattening the Short-Run Trade-Off Between Inflation and Domestic Activity: The Analytics of the Effects of Globalization." Kiel Working Paper No. 1363 (June). Kiel: Kiel Institute for World Economics. 
Razin, A., and A.K. Rose. 1994. "Business Cycle Volatility and Openness: An Exploratory CrossSectional Analysis." In L. Leiderman and A. Razin, eds. Capital Mobility: the Impact on Consumption, Investment, and Growth. Cambridge: Cambridge University Press.

Rodrik, D. 1998. "Why Do More Open Economies Have Bigger Governments?" Journal of Political Economy 106(5): 997-1032.

Rogoff, K. 2003. Globalization and global disinflation. Federal Reserve Bank of Kansas City Economic Review 4th quarter issue: 45-78.

Romer, D. 1993. "Openness and Inflation: Theory and Evidence." Quarterly Journal of Economics 108: 869-903.

Shah, A. and I. Patnaik. 2009. "Asia Confronts the Impossible Trinity." Mimeo, NIPFP-DEA.

Shambaugh, Jay C. 2004. "The Effects of Fixed Exchange Rates on Monetary Policy." Quarterly Journal of Economics 119 (February): 301-352.

Tornell, A. and A. Velasco. 2000. "Fixed Versus Flexible Exchange Rates: Which Provides More Fiscal Discipline?" Journal of Monetary Economics 45(2): 399-436.

Willett, T. 2003. "Fear of Floating Need Not Imply Fixed Exchange Rates." Open Economies Review 14: 77-91.

Windmeijer, F. 2005. "A finite sample correction for the variance of linear efficient two-step GMM estimators." Journal of Econometrics 126: 25-51. 


\section{About the Paper}

Joshua Aizenman, Menzie D. Chinn, and Hiro Ito find that the trilemma policy configuration does not matter for per capita economic growth, but does matter for output volatility and the medium-term level of inflation. Trilemma policy configurations and external finances are found to affect output volatility mainly through the investment channel. While pursuing exchange rate stability could naturally stabilize the real exchange rate movement, it could also make investment volatile, though the volatility-enhancing effect of exchange rate stability on investment can be cancelled by holding higher levels of international reserves. Asian emerging market economies are found to be equipped with macroeconomic policy configurations that help the economies to dampen the volatilities in both investment and real exchange rate.

\section{About the Asian Development Bank}

ADB's vision is an Asia and Pacific region free of poverty. Its mission is to help its developing member countries substantially reduce poverty and improve the quality of life of their people. Despite the region's many successes, it remains home to two thirds of the world's poor: 1.8 billion people who live on less than $\$ 2$ a day, with 903 million struggling on less than $\$ 1.25$ a day. ADB is committed to reducing poverty through inclusive economic growth, environmentally sustainable growth, and regional integration.

Based in Manila, ADB is owned by 67 members, including 48 from the region. Its main instruments for helping its developing member countries are policy dialogue, loans, equity investments, guarantees, grants, and technical assistance.

Asian Development Bank

6 ADB Avenue, Mandaluyong City

1550 Metro Manila, Philippines

www.adb.org/economics

ISSN: 1655-5252

Publication Stock No. 